\title{
ESTADO, IGLESIA Y SOCIEDAD EN LA MONARQUÍA HISPANA DE CARLOS IV. LAS APRECIACIONES DE UN EMBAJADOR AUSTRIACO EN MADRID
}

\author{
POR \\ LuIs ÁlVAREZ GuTIÉRREZ
}

Instituto de Historia CSIC

\section{RESUMEN}

Este trabajo propone un análisis historiográfico del contenido de los despachos diplomáticos enviados a Viena por el embajador imperial, Juan Federico de Kageneck, acreditado ante la Corte de Carlos IV. Corresponden a los siete primeros años de aquel reinado (1789-1795). Proporcionan datos, apreciaciones y comentarios sobre el estado de la monarquía hispana de la época en sus aspectos institucionales, administrativos, políticos, económicos, sociales, religiosos, militares, relaciones internacionales, e intereses geoestratégicos. El diplomático austríaco dedica atención preferente a las repercusiones de la Revolución francesa en España; a las medidas adoptadas por las autoridades españolas para contrarrestar la difusión de las ideas subversivas, tanto en la metrópoli, como en los territorios de ultramar, con especial referencia al papel destacado jugado por el clero, como baluarte ideológico y moral frente a los embates del proceso revolucionario francés; a la actitud de España ante las iniciativas de formar una coalición internacional contra la Francia revolucionaria; y a su posterior entrada en guerra contra la Francia de la Convención (1793-1795).

Palabras ClaVE: Siglo XVIII, España, Carlos IV, Austria, Kageneck, Revolución francesa.

\section{AbSTRaCt}

This writing deals with an historiographical analysis of the contents of the diplomatic dispatches sent to Vienna by the imperial ambassador, John Frederick count of Kageneck, accredited at the Court of Charles IV. They concern to the first 


\begin{abstract}
seven years of that reign (1789-1795). Provide issues, appreciations, and commentaries about the conditions of the contemporaneous Hispanic kingdom in the matter of institutional, administrative, political, economic, social, religious, military affairs, international relations and geostrategical interests. The Austrian diplomat pays much attention to the consequences of the French revolution in Spain; to the measures adopted by the Spanish authorities against the spread of the subversive ideas, as much in the metropolis, as in the overseas dominions, with special reference to the outstanding rôle played by the clergy, as the ideological and moral bulwark against the impetuous attacks of the French revolutionary activity; to the attitude of Spain with regard to the purpose of forming an international coalition against the revolutionary France; and to the later access of Spain in the war against the France of the Convention (1793-1795).
\end{abstract}

KEY WORDS: XVIII ${ }^{\text {th }}$ century, Spain, Charles IV, Austria, Kageneck, French Revolution.

Pasado un tiempo prudencial desde que apareciera el sexto volumen de esta colección documental ${ }^{1}$, sin visos de que nuevos volúmenes vengan a enriquecer la serie en un próximo futuro, parece el momento oportuno para proceder a un análisis detallado de sus contenidos y de su significado historiográfico. Desgraciadamente, todo hace barruntar que el proyecto inicial, previsto para recoger la correspondencia diplomática de los representantes de Viena en la capital de España durante el reinado de Carlos IV (1788-1808), vaya a quedar reducido a estos seis volúmenes, que apenas cubren el primer tercio de aquel período. Así lo da a entender el propio transcriptor y anotador de los textos en el estudio preliminar que acompaña al último volumen.

No obstante haber quedado truncada la serie, el valor testimonial de los documentos publicados hasta ahora merece que nos ocupemos de ella con cierto detenimiento, y la presentemos a los lectores de Hispania Sacra. Constituyen, sin duda, un buen elemento de juicio para una mejor comprensión de una etapa decisiva en la historia de España, su transición del Antiguo Régimen a la etapa liberal. Etapa histórica puesta de actualidad, a principios del presente año de 2002, en un ciclo de conferencias, que bajo el título, «El fin del Antiguo Régimen», ha patrocinado la Fundación Santander Central Hispano, con la participación de destacados historiadores, miembros de la Real Academia de la Historia, como Carmen Iglesias y Gonzalo Anes; o en la exposición, inaugura-

1 Hans JURETSCHKE - Hans-Otto KLEINMANN, Berichte der diplomatischen Vertreter des Wiener Hofes aus Spanien in der Regierungszeit Karls IV. (1789-1808) /Despachos de los representantes diplomáticos de la Corte de Viena, acreditados en Madrid durante el reinado de Carlos IV (1789-1808), Madrid: Deutsch-Spanisches Forschungsinstitut der Görres-Gesellschaft / Fundación Deutsche Stiftung y Consejo Superior de Investigaciones Científicas, 1990-1999, 6 vols., LII+558, XXXVIII+600, XLII+582, XXX+608, XXII+528, y XLVI+483 págs.

Mundo moderno

Hispania Sacra 55 (2003) 
da a finales del mismo año en el Museo Arqueológico Nacional, después de estar abierta, desde agosto, en la ciudad de Mahón, para conmemorar el segundo centenario del Tratado de Amiens, en virtud del cual se recuperaba la isla de Menorca. También está de actualidad uno de los grandes protagonistas de aquella experiencia histórica, el rey Carlos IV, que ocupa el centro de atención en esta correspondencia diplomática, y ha sido objeto de estudio en obras de reciente aparición, como la de T. Egido, sobre su reinado, y la de M. L. LópezVidriero sobre los gustos bibliófilos de aquel monarca, cuando aún era Príncipe de Asturias.

Con la publicación de estos fondos documentales, sus editores, los profesores Juretschke y Kleinmann, se proponen dar a conocer la correspondencia diplomática de los embajadores austríacos acreditados en la Corte madrileña de Carlos IV. Viene a continuar la anterior colección, de iguales características y con los mismos responsables, dedicada al reinado de Carlos $\mathrm{III}^{2}$. De ésta última existen sendos análisis en la revista hermana de Hispania: primero, con motivo de la aparición de los primeros tomos ${ }^{3} ;$ y, luego, al concluir, en 1988, la publicación de la voluminosa serie, que comprende catorce gruesos volúmenes ${ }^{4}$.

El sexto volumen, que, de momento, parece cerrar la serie, contiene los despachos del conde Juan Federico de Kageneck, cincuenta y cinco en total, correspondientes al año 1795 , que se suman a los 339 publicados en los cinco volúmenes anteriores. El primero de estos recoge ochenta despachos comprendidos entre el 5 de enero de 1789 y el 28 de junio de 1790. El segundo contiene los noventa y cuatro enviados por el mismo embajador desde el 5 de julio de 1790 al 26 de diciembre de 1791. En el tercero están incluidos los cincuenta y seis despachos del año 1792. El cuarto acoge los cincuenta y siete del 1793; y el quinto los cincuenta y dos del 1794. Forman un importante conjunto de trescientas noventa y cuatro piezas de documentación diplomática, que cubren siete años de la historia española en el último docenario del siglo XVIII.

El envío de los despachos a Viena solía hacerse con una cadencia bastante regular de uno por semana. En ellos ocupa un lugar preferente la información acerca de la percepción e interpretación del proceso revolucionario francés por parte de los dirigentes españoles y del propio embajador; de las reacciones de

2 Berichte der diplomatischen Vertreter des Wiener Hofes aus Spanien in der Regierungszeit Karls III (1759-1788) / Despachos de los representantes diplomáticos de la Corte de Viena en Madrid durante el reinado de Carlos III (1759-1788), Madrid: Goerres-Gesellschaft y Consejo Superior de Investigaciones Científicas 1970-1988, 14 volúmenes.

3 Manuel ESPADAS BURGOS, «El retorno de la historia diplomática: los despachos de los embajadores austríacos ante Carlos III», en Hispania, 33 (1973) 665-673.

4 Luis ÁlVAREZ GUTIÉRREZ, «Una fuente diplomática austríaca para el estudio del reinado de Carlos III», en Hispania, 48 (1988) 1101-1113. 
la sociedad española en sus distintos estamentos, con particular referencia al clero y a su papel en aquella coyuntura histórica; y de las repercusiones de aquellos acontecimientos en España, tanto en su política interna, como en su acción exterior.

En este sentido, puede servir de eje, para el análisis de los contenidos, el tercer volumen, que corresponde al año de 1792. Es el año que marca la progresiva radicalización del movimiento revolucionario francés, con el inicio de las hostilidades bélicas frente a la enemiga exterior, el asalto a las Tullerías, la Commune parisina, la detención y encarcelamiento de Luis XVI, la apertura de la Convención Nacional y la proclamación de la república.

En los informes del diplomático vienés queda patente la creciente preocupación de los gobernantes españoles por el giro que estaba tomando lo acaecido al otro lado de la frontera pirenaica, particularmente por la suerte que pudieran correr Luis XVI y la familia real. Las repercusiones de aquellos sucesos en España quedan plenamente reflejadas en estas páginas; al igual que las medidas adoptadas por las autoridades españolas, para contrarrestar la difusión de las ideas subversivas, tanto en la metrópoli, como en los territorios de ultramar. Bien a principios de aquel año se registra la creciente presencia de emigrados galos, nobles y clérigos ${ }^{5}$, cuyos testimonios contribuían a acrecentar los temores suscitados por los cambios políticos, que se estaban produciendo en el país vecino. Como es lógico, dedica atención preferente a la postura adoptada por España ante las primeras iniciativas de formar una coalición internacional contra la Francia revolucionaria, una de las claves para interpretar los tres cambios de gobierno ocurridos en España a lo largo de aquel año, con la sustitución de Floridablanca por Aranda, y la de éste por Godoy. Síntoma, a su vez, de las dudas e indecisiones, que aquejaron a la corte española, cogida a la improvista por lo ocurrido en Francia, sobre la mejor manera de hacer frente a lo que se les venía encima.

Obviamente, los tres personajes, encargados de dirigir la política exterior del país, son objeto de constantes referencias en esta correspondencia de Kageneck con Viena. Se muestra muy crítico con el conde de Aranda, a quien considera próximo al club de los jacobinos, «con los que convivió durante varios años en París, especialmente con Condorcet y sus correligionarios $»^{6}$. No obstante, admite que la política de neutralidad frente a la Francia revolucionaria, auspiciada por Aranda, respondía no tanto a sus simpatías ideológicas, cuanto al propósito de ganar tiempo e impedir un choque con el ejército francés a la espera de que fueran Austria y Prusia las que se encargaran de esta

5 En el despacho, $\mathrm{n}^{\circ}$ 4, del 23 de enero de 1792, manifiesta que «el número de nobles y clérigos que emigran desde ese país a España es muy elevado», en vol. III, p. 30.

6 En el despacho, $\mathrm{n}^{\circ} 42$, del 1 de octubre de 1792, vol. III, p. 335.

Mundo moderno

Hispania Sacra 55 (2003) 
tarea. Esta constatación no le impide, sin embargo, proclamar paladinamente su satisfacción por la destitución del noble aragonés, hasta el punto de afirmar que «es una circunstancia afortunada el que este personaje, extremadamente peligroso, fuera apartado del Ministerio» ${ }^{7}$. Las críticas al conde de Aranda, objeto de especial ojeriza por parte del diplomático austríaco por considerarlo defensor de una política de neutralidad hacia la Francia revolucionaria y proclive a simpatizar con sus principios ideológicos, siguen presentes, de modo constante, en los despachos de los años siguientes. Le acusa de ser el principal causante de las dudas e indecisiones de la política española hacia el país vecino levantado en armas contra el orden establecido.

En cambio, valora positivamente la actitud de Floridablanca, al que define como adversario declarado de los principios inspiradores de la revolución francesa. Se muestra comprensivo hacia las vacilaciones y reticencias de su política para formar un frente de las monarquías europeas, que pusiera fin al foco revolucionario galo.

En cuanto a lo que cabía esperar de Manuel Godoy, si bien manifiesta que era una cuestión difícil de responder de antemano, él abrigaba pocas esperanzas de que pudiera hacer frente con éxito a problemas tan complicados, habida cuenta de su juventud, su falta de inteligencia, instrucción y experiencia, así como de las circunstancias de su nombramiento, que le restaban apoyos en la sociedad española ${ }^{8}$. En este caso, a diferencia de lo que ocurre con Aranda, las posteriores apreciaciones sobre Godoy cambian de signo. A media que el duque de la Alcudia y Sueca - luego, Príncipe de la Paz - se distancia de la política preconizada por su inmediato antecesor en el cargo, Kageneck presenta una imagen más positiva del valido, bastante alejada de la que suele ofrecer la historiografía española tradicional, sometida actualmente a profunda revisión en este punto'.

En este campo de las relaciones entre la España de Carlos IV y la Francia revolucionaria aparece reiteradamente, en los despachos del embajador vienés, otro personaje clave. Se trata de Juan Francisco de Bourgoing, conocido autor

7 En el despacho, $\mathrm{n}^{\circ}$ 52, del 3 de diciembre de 1792, vol. III, p. 421.

8 En ibidem.

9 Revisión que ha dado pasos decididos el año pasado, con ocasión del sesquicentenario de su muerte (1.10.1851): una exposición, en el Museo Nacional de Arte Romano en Mérida, sobre algunas de las facetas de la política cultural de Carlos IV y su Secretario de Estado; un cingreso celebrado en Castuera, con actas coordinadas por LA PARRA LÓPEZ, Emilio y MELÓN JiMÉNEZ, Miguel A., Manuel Godoy y la Ilustración, Mérida: Editora Regional de Extremadura, 2001; un artículo de Alicia María CANTO, «Godoy: una justa y necesaria revisión», en $A B C, 29-12-2001$, p. 66; y, de más reciente aparición, el libro de Emilio LA PARRA, Manuel Godoy. La aventura del poder, Barcelona: Tusquets, 2002, donde en 582 págs. recorre la peripecia vital del personaje y analiza su trayectoria al frente de los destinos del país en un intento por reivindicar su actuación pública; cuenta con un enjundioso prólogo del profesor Carlos Seco Serrano. 
del Tableau de l'Espagne Moderne, que, publicado anónimo en 1788, pronto se convirtió en obra de obligada consulta para cuantos, en aquella época, se interesaban por conocer la realidad española ${ }^{10}$. No en vano era Bourgoing buen conocedor de la geografía, de la historia, de la economía y de la cultura españolas, gracias a su larga estancia en España, que se remontaba al año 1777, como secretario de embajada y encargado de negocios. Fue el representante diplomático de la Francia revolucionaria en Madrid, aunque sin status diplomático definido y reconocido hasta principios de 1792, para tener que abandonar su puesto el 21 de febrero de 1793 tras la ruptura de relaciones entre Madrid y París a consecuencia del ajusticiamiento de Luis XVI ocurrido un mes antes.

Kageneck no perdió de vista un momento las andanzas de su colega francés en la Corte española. Siguió atentamente y comunicó puntualmente a Viena las gestiones y esfuerzos de este diplomático por mantener abiertas las vías del diálogo entre París y Madrid aun después de la ruptura del Pacto de Familia. Los datos proporcionados por Kageneck sobre la actividad diplomática y las ideas políticas de Bourgoing constituyen un buen complemento y contrapunto a los ofrecidos por su colega prusiano, el barón David Alphonse von SandozRollin ${ }^{11}$; y a los contenidos en los estudios de Grandmaison y de Chaumié sobre las relaciones franco-españolas en aquel período ${ }^{12}$.

Otra cuestión expuesta en este volumen, también en estrecha relación con la revolución francesa, era la situación financiera de España. Ésta interesaba sobremanera en Viena ante la perspectiva de que pudieran hacerse realidad las promesas, hechas por Floridablanca, de apoyar una alianza internacional antirrevolucionaria con aportación de fondos para financiar la participación militar de Suecia. A instancia expresa del príncipe de Kaunitz, canciller austríaco (1753-1792), el embajador Kageneck se ocupó específicamente del tema en

10 Jean-François de BOURGOING, Nouveau voyage en Espagne, ou Tableau de l'état actuel de cette monarchie, Paris: Chez Regnault, 1788, 3 vols.; fue reeditada en 1789, 1797, 1803 y 1807; las tres últimas con el título de Tableau de l'Espagne Moderne; no tardó en ser traducida al alemán, Neue Reisen durch Spanien ..., Jena: J.M. Manke, 1789-1800, 4 vols. y al inglés, Modern State of Spain ..., London: J. Stockdale, 1808, 4 vols., precedida y seguida de mas ediciones en Londres y Dublín.

11 En ellos está basada la obra de Hermann BAUMGARTEN, Geschichte Spaniens zur Zeit der französischen Revolution. Mit einer Einleitung über die innere Entwicklung Spaniens in 18. Jahrhundert, Berlin: G. Reimer, 1861. Es también autor de la Geschichte Spaniens von Ausbruch der französischen Revolution bis auf unsere Tage, Leipzig: Verlag von S, Hirzel, 1865-1871, 3 vols.. Comienzan con la subida al trono de Carlos IV y llegan hasta la primera guerra carlista. Los referidos despachos podrían ser localizables en el Geheimes Staatsarchiv Preussischer Kulturbesitz, en Berlín.

12 Charles-Alexandre GEOFFROY DE GRANDMAISON, L'ambassade française en Espagne pendant la Révolution (1789-1804), Paris: E. Plon, Nourrit et Cie, 1908; podría añadirse La France et l'Espagne pendant le premier Empire (Archives espagnoles), Besançon: Impr. de P. Jacquin, 1899. Jacqueline CHAUMIÉ, Les relations diplomatiques entre l'Espagne et la France de Varennes à la mort de Louis XVI, Bordeaux: Féret et Fils, 1857.

Mundo moderno

Hispania Sacra 55 (2003) 
dos ocasiones, en los despachos del 20 de febrero y 15 de mayo ${ }^{13}$. En ambos transmite a la Corte vienesa datos interesantes sobre las bases económicas de la economía española: el flujo de metales preciosos, oro y plata, amonedados o en lingotes, procedentes de "sus ricas posesiones en América»; y la explotación de minerales en la propia península, como el cobre y, sobre todo, el mercurio en las minas de Almadén y Almadenejos.

En relación con el laboreo del mercurio de Almadén, de su venta y transporte, hace una extensa exposición con referencias históricas y detalles muy precisos sobre costes de producción, sobre salarios y sobre aspectos técnicos y administrativos de las explotaciones. Subraya, en particular, la presencia de obreros especializados y jefes administrativos traídos de Sajonia. Son apuntes aprovechables para abordar estudios, escasamente cultivados hasta ahora, acerca de las relaciones industriales, laborales, científicas y técnicas entre España y los Estados germanos en aquella centuria y principios de la siguiente ${ }^{14}$. En relación con estas explotaciones salen a relucir nombres de profesores e investigadores de la época, que destacaron en ciencias, como Geología, Mineralogía y Química, cuyos descubrimientos y mejoras técnicas o administrativas sirvieron para un mejor aprovechamiento de aquellos recursos mineros ${ }^{15}$.

Las apreciaciones, que formula sobre la situación económica del país, discrepan de los juicios emitidos por los economistas, a comenzar por el propio Adam Smith, que impugnan la idea de la proverbial riqueza de España derivada de los ingresos por los metales preciosos americanos. En contra de los que aseveraban que el oro y la plata llegados desde las Indias pasaban de seguida a otros países, de modo que España padecía de escasez de dinero en efectivo,

$13 \mathrm{~N}^{\circ} 9$ y 22 , en vol. III, págs. 56-65 y $152-184$.

14 Esta situación está ahora en proceso de cambio. Un investigador del CSIC, Miguel Ángel Puig-Samper, dirige actualmente un proyecto de investigación, financiado por el Ministerio de Ciencia y Tecnología en el marco del Programa General del Conocimiento, que tiene por objeto estudiar «Las relaciones científicas hispano-alemanas en la época ilustrada». Iniciativa que ya ha dado lugar a la publicación de trabajos, del director y sus colaboradores, a los que se hace referencia en la nota 84.

15 Entre los mencionados, tanto españoles, como extranjeros, aparecen los nombres de Abuerne, Delhuyar, Gutiérrez Bueno, Chabaneau, Born, Hoppensak, Friedrich Meyer, o Nordenpflicht. Para conocer el papel de algunos expertos extranjeros en el establecimiento de instituciones científicas en la España del siglo XVIIII es de gran utilidad un artículo reciente de Dolores PARRA y, Francisco PELAYO «Christian Herrgen y la institucionalización de la mineralogía en Madrid», en Asclepio, Madrid: CSIC, 48 (1996) 163-181, o el anterior de Antonio RUMEU DE ARMAS, «La Real Escuela de Mineralogía de Madrid (1789-1808)», en Hispania, Madrid: CSIC, 39 (1979) 301-335. Sobre la institucionalización de otras ciencias puede verse José R. BERTOMEU SÁNCHEZ, y Antonio GARCÍA BELMAR,, «Pedro Gutiérrez Bueno (1745-1822) y las relaciones entre la Química y la Farmacia durante el último tercio del siglo XVII», en Hispania, Madrid: CSIC, 61/2 (2001) 539-562. Más en general, para el desarrollo de los conocimientos científicos en aquella centuria, la obra de Manuel SELLÉS, José Luis PESET y Antonio LAFUENTE, Carlos III y la ciencia de la Ilustración, Madrid: Alianza Editorial, 1988. 
Kageneck se atreve a afirmar «que en ningún país, incluida Inglaterra — de la que era buen conocedor con cuatro años de servicios diplomáticos en Londres-, es dado hallar más dinero contante y sonante que en España» ${ }^{16}$. En apoyo de su aserto señalaba que «la gente más común, aun en pequeños pueblos, lleva consigo una bien abastecida bolsa» ${ }^{17}$. Es un buen tema de debate a dilucidar por los expertos en la materia. El asunto de las finanzas en España sigue presente en los informes de los volúmenes siguientes en relación con la llegada de nuevas remesas desde América ${ }^{18}$, o con la emisión de vales reales, que no tardaron en sufrir una creciente devaluación.

En cambio, llama la atención, a renglón seguido, sobre la carestía de la vi$\mathrm{da}$, con unos altos precios en productos de primera necesidad, como el pan, la carne y el vino, cuyo consumo - dice- «determina, en todas partes, el índice del bienestar». Señala, por ejemplo, que el pan en Madrid era cuatro veces más caro que en Viena ${ }^{19}$. La exposición de éste y otros datos sobre bienes de consumo le da ocasión para ofrecer, una vez más, sus puntos de vista acerca de la sociedad española. La califica de frugal en la comida, sobria y austera, poco dada al lujo, que, «a diferencia de lo que ocurre en otros países, aún no ha echado raíces en provincias, si bien en Madrid y en algunas ciudades costeras el mundo femenino, que muestra una gran afición por la moda francesa e inglesa, causa desequilibrios en algún que otro presupuesto familiar» ${ }^{20}$. En otro orden de cosas, nos presenta a un pueblo español muy apegado a sus cosas, con una mentalidad muy tradicional y, en consecuencia, poco amigo de las novedades, que atribuye a pereza mental e indolencia ${ }^{21}$.

Junto a estas informaciones, de índole económica y sociológica, no faltan observaciones sobre la estructura política de la monarquía hispana. Considera

\footnotetext{
16 En despacho, $\mathrm{n}^{\circ}$ 9, del 20 de febrero de 1792, III, p. 57.

17 En ibidem.

18 Sirva de ejemplo el anejo $\mathrm{C}$ al despacho, $\mathrm{n}^{\circ} 4$, del 27-1-1795, VI, pp.40-42, que contiene una lista detallada de los navíos arribados al puerto de Cádiz, durante el año 1794, procedentes de América, con indicación del valor del oro y plata acuñado, en barras y alhajas, para el rey y para particulares. La suma total alcanzaba la elevada suma de casi veintiocho millones de pesos, de los que poco más de un tercio correspondían a las arcas reales, y el resto a particulares. En el comentario a estas cifras advertía que «pocos Estados podían disfrutar de tan considerables ingresos, que debieran contribuir poderosamente al bienestar de esta monarquía», en ibidem, p. 39.

19 En despacho, n 9, del 20 de febrero de 1792, III, p. 58.

20 En ibidem.

21 Mientras los franceses e italianos, comenta, llevados de un espíritu innovador, «se dejan tentar por las novedades, con lo que esperan mejorar su suerte, los españoles, en cambio, rechazan las innovaciones, incluso si suponen mejoras, y lo sacrifican todo a una tranquilidad, próxima a la pereza; son, pues, devotos de las viejas instituciones y usanzas y menosprecian casi de modo general lo que otros llaman Ilustración. La inacción es su máxima aspiración, pero si lo arrancan de su indolencia, hará frente al poder con toda decisión, y se mostrará furibundo y muy peligroso», despacho, $\mathrm{n}^{\circ} 7$, del $17 \mathrm{de}$ febrero de 1795, VI, p. 63.
}

Mundo moderno

Hispania Sacra 55 (2003) 
que su principal soporte, para sobrellevar los difíciles momentos provocados por el proceso revolucionario desencadenado allende el Pirineo, era el amor del pueblo hacia la persona del rey, respaldado por el clero. En cambio, habla de una administración recargada, desordenada y, por ende, ineficiente; minada por la corrupción en forma de favoritismo y nepotismo, en las escalas altas, y por la desidia de los funcionarios mal pagados, fácil presa del cohecho o del soborno. Es motivo de descontento y animosidad entre el pueblo, que puede desembocar, advierte, en un levantamiento de imprevisibles consecuencias; riesgo frenado, a su entender, por la veneración popular hacia la institución monárquica y por la acción del clero. Provoca, a su vez, la crítica de los sectores sociales más conscientes, que pueden convertirse en caldo de cultivo para la difusión del ideario revolucionario. En cuanto al estamento nobiliario deja constancia de que en sus filas no faltaban elementos, que, con el conde de Aranda a la cabeza, compartían ideas próximas a las que dieron impulso a la revolución francesa.

Tampoco el ejército, a juicio de Kageneck, estaba a la altura de las circunstancias. No ofrecía garantías de éxito en el caso de un enfrentamiento armado con los vecinos del norte. Adolecía de parecidos defectos a los señalados para el aparato administrativo: plétora de jefes y oficiales, en cuya selección y promoción primaban el favoritismo cortesano y el amiguismo ministerial. Se hace eco del extendido tópico de que «en muchos aspectos es difícil encontrar mejor soldado que el español salido del pueblo llano»"2 , al que califica de «valiente, duro, obediente - un tanto indisciplinado a veces- y sobrio ${ }^{23}$. Pero, al mismo tiempo, comenta la escasa disponibilidad de la sociedad española para el servicio militar, lo que causaba graves problemas de reclutamiento ${ }^{24}$. Mejor imagen ofrecía de la armada.

Otro tema recurrente, en los informes de Kageneck, concierne al clero y a su papel en el contexto político, social e ideológico de la época. Sus anotaciones sobre el particular versan sobre su posición dominante en aquella sociedad estamental; su poder económico; y su destacado papel, como sostén del mencionado afecto popular hacia el rey, como guardián de los valores tradicionales frente a las ideas innovadoras de la Ilustración, y como baluarte ideológico y moral frente a los embates de la revolución francesa. Reitera la idea, ya expuesta en los dos tomos anteriores, de la gran influencia del clero sobre el pueblo llano. Idea

22 En despacho, $\mathrm{n}^{\circ}$ 9, del 20 de febrero de 1792, III, p. 58.

23 En despachos, $\mathrm{n}^{\circ}, 12$ y 39, del 11 del marzo y del 19 de agosto de 1793, IV, pp. 84 y 328.

24 «El español tiene una total aversión hacia el servicio de las armas, por lo que resulta difícil proceder a la leva de reclutas», frase contenida en el segundo de los despachos citados en la nota anterior, en ibidem. Dificultades que ya había comentado anteriormente, en despacho, $n^{\circ} 37$, del 5 de agosto de 1793, IV, p. 310. 
que se convierte en ritornelo en los tres siguientes. Lo considera un factor decisivo en la estabilidad interna de la monarquía hispana, en medio de los peligros derivados de los cambios políticos, que se desarrollaban a ambos lados del Atlántico. Asociada al afecto del pueblo hacia el trono, la señala, concretamente, como una de las principales causas, que contribuyeron a impedir que se produjera en España un levantamiento popular, similar al ocurrido en Francia.

A este respecto, es significativo lo que comenta en uno de sus despachos del mes de octubre de 1792. Informaba allí sobre la existencia, en Madrid y en importantes ciudades portuarias, de grupos de personas, especialmente entre abogados, comerciantes y capitalistas, que, adictos a los principios de la revolución francesa, esperaban con ansiedad, un movimiento similar en España. Hecho, añade, que bien hubiera podido producirse, «si el clero, inquieto por las disposiciones de la Asamblea Nacional gala, no hubiera sabido mantener en orden al pueblo que le tiene gran respeto» ${ }^{25}$.

Esta influencia del clero se ácrecienta sobremanera durante el desarrollo de la guerra contra la Francia de la Convención. Iniciada, en el marco de la primera coalición internacional, a principios de 1793, apenas producirse el ajusticiamiento de Luis XVI, ocurrido el 21 de enero, se prolonga hasta la paz de Basilea en julio de 1795. El papel del clero adquiere entonces una nueva dimensión y adopta formas diversas. No se trata sólo de mantener alta la moral en la lucha armada contra el ejército revolucionario galo, labor desplegada asiduamente desde los púlpitos y mediante cartas pastorales de los obispos. Se extiende también a las contribuciones económicas extraordinarias para subvenir al sostenimiento financiero de la guerra. Llega a la acción directa con el reclutamiento de soldados e, incluso, la participación personal de miembros del clero en los combates, o a la intervención de la Inquisición para abortar y reprimir intentonas revolucionarias, que en América revisten, además, tintes independentistas.

Kageneck relata el caso de los franciscanos. Su superior general, el español Joaquín Company, dirigía un memorial al rey, donde designaba guerra de religión a la recién iniciada contienda contra la Francia revolucionaria y que «incumbía al clero contribuir a ella en la medida de sus fuerzas». Él, por su parte, se comprometía, en nombre de la Orden, a adelantar una considerable cantidad de dinero, que no especifica, y a reunir 5.000 hombres. El embajador añade que el rey le había manifestado su gran satisfacción por ello, no en balde había 36.000 franciscanos en sus dominios. Y comentaba, eufórico, que, «si este ejemplo es seguido por las demás Órdenes religiosas y el resto del clero, al rey no se le será difícil cubrir los costes de las campañas militares, y aumentar los contingentes de sus ejércitos ${ }^{26}$.

25 En el despacho, $\mathrm{n}^{\circ}$ 44, del 15 de octubre de 1792, III, p. 355.

26 En el despacho, $\mathrm{n}^{\circ} .1$, del 7 de enero de 1793, IV, p. 10. 
Poco después, señala que el ejemplo se extiende al clero secular. Los que desempeñan cargos más modestos entregan a la Corona los ingresos de sus beneficios, equivalentes a un año. Entre los más pudientes, el clero catedralicio de Valencia ha entregado cinco millones de reales, el de Sevilla cuatro millones y el de Toledo tres. Por otra parte, añade, se está a la espera de recibir anticipos dinerarios de obispos, arzobispos y altos dignatarios de los cabildos ${ }^{27}$. Otro tanto sucede con el clero del otro lado del Atlántico, que había abierto un crédito de treinta millones de piastras a favor del rey ${ }^{28}$.

Sobre la acción de los inquisidores para prevenir la difusión de las ideas revolucionarias recoge diferentes noticias, procedentes de Méjico. Unas hablan de la difusión de «folletos sediciosos, llevados desde Europa e impresos en español, que han sido retirados por un clero diligente». La importación y distribución de los mismos se atribuye «a súbditos norteamericanos y a habitantes de la Luisiana, aventureros franceses, en su mayor parte, que mantienen relaciones comerciales con los franceses europeos $\rangle^{29}$. Otras posteriores refieren haber sido abortada una importante conspiración. Contaba con un elevado número de conjurados, cuya mayor parte, unos trescientos, habían sido detenidos por la Inquisición. Seducidos por las mismas ideas de los revolucionarios europeos, «contrarias a las leyes, al orden y a la tranquilidad vigentes», se proponían asesinar al virrey, al arzobispo y a otros altos funcionarios del Estado, derrocar el gobierno virreinal de México e implantar un nuevo régimen «a imagen y semejanza del de los jacobinos» ${ }^{30}$.

Kageneck también testimonia el poder económico de la Iglesia en España ${ }^{31}$, y su peso específico en la vida pública española de la época. No es, pues, de extrañar que, en más de una ocasión comunique a sus superiores los esfuerzos de algunos ministros y de la propia reina para atraerse el apoyo del clero. Es llamativo lo que, sobre el particular, nos dice del conde de Aranda, que pasaba

27 En el despacho, $\mathrm{n}^{\circ} 7$, del 18 de febrero de 1793, IV, p.56. Supuesto que no tardó en cumplirse en el caso del arzobispo de Toledo, Francisco José Antonio de Lorenzana. En efecto, en el siguiente despacho, del día 25 , informa que este prelado ha ofrecido entregar al rey sus beneficios durante el tiempo que dure la guerra, salvo lo imprescindible para su modesto mantenimiento y para el acostumbrado reparto de limosnas en Toledo, ibidem, p.67.

28 En el despacho, $\mathrm{n}^{\circ}$ 57, del 16 de diciembre de 1793, IV, p. 471.

29 En el despacho, ${ }^{\circ}$ 2, del 14 de enero de 1793, IV, p. 16.

30 En el despacho, $\mathrm{n}^{\circ} 2$, del 12 de enero de1795, VI, p. 24. Adjunta, traducido al francés, un escrito, como anejo A, pp. 24-25, que ofrece amplios detalles sobre la conjura.

31 Sostiene que «el clero, especialmente los conventos guardan una increíble riqueza. Iglesias y capillas poseen grandes tesoros, que se llaman Depósitos o dinero santo. Entre las Órdenes religiosas se encuentran en toda España, especialmente en las grandes ciudades, conventos, que realizan considerables operaciones financieras en todo el mundo, dentro y fuera de Europa, de las que obtienen buenos beneficios. Aunque esta actividad ha disminuido un tanto, desde que muchos franceses y genoveses se dedican a este medio de enriquecimiento «, en el despacho, $\mathrm{n}^{\circ}$ 9, del 20 de febrero de 1792, III, p. 57. 
por ser un adversario declarado de la Iglesia. Cuando pasó a ocupar la Primera Secretaría de Estado, desde febrero de 1792, conocedor de la creciente efervescencia popular en provincias en contra suya, y consciente de tener la antipatía del clero, intentó suavizar esta animosidad. Parece ser que barajó la posibilidad de hacer volver a los jesuitas españoles residentes en Italia, en cuya expulsión había tomado parte significativa, que seguían teniendo un gran predicamento entre el pueblo ${ }^{32}$. Lo mismo ocurre con la reina María Luisa de Borbón-Parma, cuyos enredos y escándalos en la Corte no gustaban entre el pueblo. Sabedora de la gran influencia del clero en todo el reino se esfuerza por atraérselo. Se hablaba de que serían revocadas en breve las disposiciones reales, vigentes desde hacía catorce años, que permitían a la corona retener un tercio de los beneficios eclesiásticos ${ }^{33}$. Más en general, Kageneck explicaba al vicecanciller austríaco, el conde Juan Felipe Cobenzl, como, tras la caída del conde de Aranda, la corte procuraba un mayor entendimiento con aquellos elementos, principalmente el clero, que pudieran ejercer influencia sobre el pueblo, al fin de atraerse su confianza y apoyo, y evitar que el descontento popular desembocara en un levantamiento de consecuencias imprevisibles. Constataba «que actualmente son pocos los asuntos de importancia tratados en la Corte sin requerir antes el consejo de los más significados representantes del clero» ${ }^{34}$.

Esta situación era del agrado del embajador vienés, porque, a su juicio, contribuía a reforzar las defensas mentales y morales de la monarquía española frente a la creciente radicalización del empuje revolucionario galo; y podía facilitar la consecución de uno de sus empeños diplomáticos, la participación directa de España en la coalición internacional, que se estaba fraguando para poner cerco a los revolucionarios franceses e intentar la restauración monárquica en París. En este sentido, hace votos, para que el nuncio aprovechara este acercamiento entre Estado e Iglesia al fin de «apoyar las gestiones que las cortes europeas aliadas contra Francia vienen realizando ante esta Corte». Co-

32 En despacho, $\mathrm{n}^{\circ} 25$, del 4 de junio de 1792, III, p. 204; despacho, $\mathrm{n}^{\circ} 21$, del 7 de mayo de 1792, III, p. 144; despacho, $\mathrm{n}^{\circ}$ 44, del 15 de octubre de 1792, III, p. 355. La expulsión de los jesuitas de los dominios españoles y sus consecuencias ha ocupado recientemente la atención de EGIDO, Teófanes y Isidoro, PINEDO Las causas "gravísimas» y secretas de la expulsión de los jesuitas por Carlos III, Madrid: Fundación Universitaria Española, 1994, y cuenta con una publicación más reciente, de carácter colectivo, Manfred TIETZ (ed.), Los jesuitas españoles expulsos. Su imagen y su contribución al saber sobre el mundo hispánico en la Europa del siglo XVIII, Madrid/Frankfurt: Iberoamericana/Vervuert, 2001, donde en 712 págs., 27 especialistas exponen una amplia temática sobre el particular. Un excelente ensayo, sobre el quehacer de una Orden religiosa en aquellos tiempos de cambio y zozobra, puede verse en Valentí SERRA DE MANRESA, Els caputxins de Catalunya, de l'adveniment borbònic a la invasió napoleònica: vida quotidiana i institucional, actituds, mentalitat, cultura (1700-1814), Barcelona: Facultat de Teologia de Catalunya / Editorial Herder, 1996.

33 En despacho, $\mathrm{n}^{\circ} 32$, del 23 de julio de 1792, III, pp. 252-253.

34 En el despacho, $\mathrm{n}^{\circ}$ 54, del 17 de diciembre de 1792, III, p. 437. 
menta «que sería muy útil que el Nuncio recibiera órdenes» en este sentido ${ }^{35}$. «Buen conocedor del país, de la Corte y del clero», nadie, mejor que Vincenti Mareri, representante de la Santa Sede en Madrid desde 1785 - y, antes, entre 1768 y 1773, auditor en la Nunciatura - para llevar a cabo esta misión.

Se hace, igualmente, eco de las leyes, que afectaban a los privilegios del clero, o se proponían emprender reformas en la Iglesia española. En uno de sus despachos de 1795 comunicaba a Viena que un decreto real del 20 de diciembre de 1794 disponía que todos los tribunales y juzgados eclesiásticos, incluidos los de la Inquisición, debían utilizar papel sellado, al igual que lo hacían los equivalentes civiles. Comentaba Kageneck que esta disposición, lucrativa para el Estado, suponía una gran novedad «en este Reino, donde el clero disfruta de tantas prerrogativas $»^{36}$. En otro despacho posterior, alude a los proyectos de reforma eclesiástica, que barajaba el gobierno. Para la realización de los mismos, habían conseguido que el papa expidiera tres bulas. Una de ellas permitía la reducción del número de conventós; otra autorizaba la división de las grandes diócesis en otras más pequeñas; una tercera concedía al rey permiso para secularizar los bienes de la Iglesia y consignar a los miembros del clero un sustento anual proporcionado. El excedente se dedicaría a la cancelación de la deuda del Estado y al pago de intereses. Es un claro antecedente de posteriores proyectos de desamortización eclesiástica. Aunque consideraba estas medidas muy beneficiosas para el Estado, a juicio del diplomático austríaco no era muy oportuno introducir semejantes reformas en un momento, «cuando el clero goza de una gran influencia en toda la nación, y en el que sería muy peligroso aumentar las de ya por sí numerosas desavenencias con un estamento tan importante» ${ }^{37}$.

Las referencias al clero español, contenidas en los informes de Kageneck, no tienen sólo carácter colectivo. Por sus páginas desfilan también destacadas figuras de la Iglesia española de la época. Cabe mencionar, entre otras, la de Francisco de Lorenzana e Irauregui (†1804), arzobispo de Toledo, desde 1772, anteriormente arzobispo de Méjico, cardenal desde 1789 y Gran Inquisidor entre 1794 y 1797 , cuyas aportaciones al sostenimiento de la guerra, ya referi-

\footnotetext{
35 En ibidem.

36 En el despacho, $\mathrm{n}^{\circ} 4$, del 27 de enero de 1795, VI, p.40.

37 En despacho, $\mathrm{n}^{\circ} 49$, del 17 de noviembre de 1795, VI, p. 317. Esto mismo debió pensar el propio Godoy. Lo cierto es que, poco después, Kageneck informaba que el ministro español, ante el creciente descontento contra él, intentaba aproximarse al clero «y ya no se hablaba de las aborrecidas bulas», en el despacho, $\mathrm{n}^{\circ} 52$, del 8 de diciembre de 1795, VI, p. 361. Las tensiones entre Estado e Iglesia por este y otros proyectos de reforma eclesiástica fueron frecuentes en este tiempo, como las ocurridas, años después, con la legislación relativa al matrimonio, promovida por el ministro Mariano Luis de Urquijo; ver al respecto, la obra de Luis SIERRA NAVA La reacción del episcopado español ante los decretos de matrimonios del ministro Urquijo de 1799 a 1813, Bilbao: Estudios de Deusto, 1964.
} 
das anteriormente, ensalza sobre manera, al igual que su labor hospitalaria hacia los eclesiásticos franceses refugiados en España ${ }^{38}$. Hay referencias ocasionales a otras personalidades eclesiásticas de España y América, como la del sucesor de Lorenzana en el arzobispado de Toledo, el miembro de la familia real, Luis María Vallabriga, más conocido con el nombre de Luis María de Borbón ${ }^{39}$; las de Sebastián Malvar y Pinto, arzobispo de Santiago de Compostela, Agustín Rubín de Cevallos, obispo de Jaén y gran inquisidor, el también inquisidor general y obispo de Astorge, Manuel Abad y Lasierra, Agustín Iñigo Abbad y Lasierra, obispo de Barbastro, Francisco Fabián y Fuero, obispo de Tlaxcala y arzobispo de Valencia, Antonio de Sentmenat y Cartella, obispo de Ávila, patriarca de las Indias, cardenal y consejero de Estado, Esteban Antonio Aguado de Rojas, obispo de Pamplona, Agustín Lezo Palomeque, arzobispo de Zaragoza, Rafael Menéndez de Luarca, obispo de Santander, e Ildefonso Núñez de Haro y Peralta, arzobispo de México; los confesores de Carlos IV, el canónigo Alonso Camacho y el franciscano Moya; o las de los nuncios Vincenti y Casoni. También está presente la figura del papa Pío VI, con indicaciones sobre su postura ante los problemas de aquellos azarosos tiempos, sin olvidar observaciones acerca de las relaciones entre España y la Santa Sede.

Estos son los puntos de mayor calado que es dado encontrar en estos informes. Naturalmente, no son los únicos, ni mucho menos. La temática contenida en ellos es muy amplia y variada. La referente a las relaciones internacionales no se limita a la Francia revolucionaria. Otras cuestiones recurrentes de política exterior son las relaciones con Gran Bretaña, tanto en su aspecto bilateral, afectado principalmente, en aquel momento, por las exigencias británicas de indemnizaciones en el asunto del Estrecho de Nootka, como en su aspecto más general, en conexión con la situación creada en Francia por el proceso

38 En el despacho, $\mathrm{n}^{\circ} 39$, del 10 de septiembre de 1792, III, pp.312-313; despacho, $\mathrm{n}^{\circ} 43$, del 8 de octubre de 1792, pp. 347-348; ver nota 27. El asunto de los refugiados es otro tema del que Kageneck se ocupa intermitentemente. Alaba, por ejemplo, el sentido de hospitalidad ejercida por el clero español con sus congéneres franceses: «le aseguran que el cardenal de Toledo dedica anualmente 30.000 florines para su distribución al clero francés refugiado en España», en el despacho, $n^{\circ} 39$, citado al principio de la nota. De este prelado acaba de ocuparse Hispania Sacra, 54 (2002) 737-800, en un artículo de Ángel FERNÁNDEZ COLLADO, «Los informes de visita ad limina del cardenal Lorenzana en Toledo (1772-1800)».

39 Este personaje cuenta con una reciente biografía debida a la pluma de Carlos M. RODRíGUEZ LÓPEZ-BREA, Don Luis de Borbón, el cardenal de los liberales (1777-1823), Toledo: Servicio de Publicaciones, Junta de Comunidades de Castilla-La Mancha, 2002. Sobre otra importante figura de la jerarquía eclesiástica española, a caballo de los siglos XVIII y XIX, puede consultarse la obra de, Ramon CORTS I BLAY, L'arquebisbe Fèlix Amat (1750-1824) i l'ultima Il-lustració espanyola, Barcelona: Facultat de Teologia de Catalunya / Editorial Herder, 1992. Más recientemente, y con carácter más general, el estudio de Joaquim M. PUIGVERT, Bisbes, Il-lustració i jansenisme a la Catalunya del segle XVIII, Girona: Universitat / Universitat de Vic, 2000.

Mundo moderno

Hispania Sacra 55 (2003) 
revolucionario en curso. Cuestiones de las que Kageneck se ocupa repetidas veces, señalando los temores y esperanzas que suscitaba un eventual acercamiento al tradicional enemigo de los intereses españoles. Son frecuentes, igualmente, las referencias a la política española con las regencias del Norte de Africa, con especial atención a los disturbios en Marruecos. No faltan noticias acerca de los problemas suscitados por el trazado de las fronteras con Norteamérica a lo largo del Mississipi, que se solucionarán, tres años más tarde, con el tratado de San Lorenzo de El Escorial ${ }^{40}$, del 27 de octubre de 1795.

Lo mismo cabe decir del contenido de los dos volúmenes anteriores y de los tres posteriores. El primero de todos recoge los pertinentes despachos, desde enero de 1789 a julio de 1790, obra del mismo embajador, Juan Federico, conde de Kageneck, que venía desempeñando su misión diplomática en Madrid desde principios de diciembre de 1786, y donde permanecerá hasta su fallecimiento en marzo de 1800. En sus primeros informes sobre el gobierno de Carlos IV refleja cómo los pasos iniciales del nuevo reinado no suponen cambio alguno, tanto en política exterior, centrada en el mantenimiento de la paz, para salvaguardar el imperio colonial español, como en las condiciones interiores del país. En cuanto a las expectativas, que podía ofrecer el nuevo monarca, es significativo que el diplomático vienés las relacione con la influencia que la reina, María-Luisa de Borbón-Parma, ejercía sobre el ánimo de Carlos IV ${ }^{41}$.

Pero, bien pronto, la crisis política en el país vecino y aliado, a la que desde septiembre se le aplica el término de revolución francesa, se convertirá en el hilo conductor de la información transmitida a Viena, señalando los efectos de la misma en España. Como indica el profesor Juretschke, en la introducción, «la primera reacción española, tal como se desprende de los comentarios de Kageneck, es una mezcla de los más diversos sentimientos; sentimientos que, partiendo de la curiosidad e interés iniciales, se tornan inquietud y que, desde un principio de alegría y alivio por el debilitamiento del aliado francés, demasiado incómodo, desembocan en un silencio total sobre sucesos considerados excesivamente amenazadores $\rangle^{42}$.

En la misma línea, acentuada ${ }^{43}$, se desarrolla la información contenida en el segundo volumen, que abarca desde julio de 1790 a diciembre de 1791. A destacar, también, la información relativa a las relaciones entre España y Gran Bretaña centradas en la cuestión del Estrecho de Nootka. Tras amenazar con

40 Con ocasión de su bicentenario, el embajador de los Estados Unidos en España, Richard N. Gardner, publicó un amplio recordatorio en el $A B C$ del 27-10-1995: «Doscientos años desde el Tratado de San Lorenzo», p.36.

41 En el despacho, $\mathrm{n}^{\circ} 1$, del 5 de enero de $1789, \mathrm{I}, \mathrm{p} .7$.

42 Vol. I, p. XXV.

43 En el despacho, no 14, II, pp. 205-243. 
un enfrentamiento bélico, encuentra un arreglo provisional con la convención del 28 de octubre de 1790. Entre los despachos, dedicados al tema, tiene especial relevancia uno del 14 de marzo de 1791. En él Kageneck hace un detallado análisis del citado acuerdo hispano-británico; sobre su trasfondo históricopolítico; así como sobre su alcance y repercusiones, nada favorables, a juicio del diplomático austríaco, para los intereses y para la presencia de los españoles en el continente americano. En temas de política interior, alcanzan especial relieve, en las consideraciones de Kageneck, los disturbios y revueltas populares en Galicia, de los que se ocupa en varios despachos. Es de señalar que, en este segundo volumen, se incluyen trece despachos (abril-noviembre de 1790) del cónsul general de Austria en España, Paolo Greppi, redactados en francés, y que giran en torno a las relaciones con Francia y Gran Bretaña ${ }^{44}$.

En los despachos de los tres volúmenes finales, el cuarto, el quinto y el sexto, pertenecientes a los años 1793, 1794 y 1795, el tema, que ocupa la máxima atención del representante imperial en Madrid son los acontecimientos, que marcan el desencadenamiento de la guerra entre España y la Francia revolucionaria de la Convención, su desarrollo y el tratado de paz, que puso punto final a la misma. El fracaso en las gestiones para salvar la vida de Luis XVI conduce a la ruptura de las relaciones, a la declaración formal del estado de guerra por ambas partes y al inicio de las hostilidades militares por mar y por tierra. A su entender, fue una guerra emprendida con escaso entusiasmo por parte del gobierno español; una guerra impuesta más por motivos morales de solidaridad dinástica $\mathrm{y}$, si se quiere, ideológica, que por unos objetivos concretos de carácter territorial o económico. De ahí las indecisiones iniciales de los dirigentes españoles señaladas y lamentadas, una y otra vez, por Kageneck. Sólo les animaba la esperanza de que los levantamientos internos o los eventuales éxitos militares de Austria y Prusia pusieran fin a un foco de infección revolucionaria, que podría poner en peligro el estado de cosas existente en la península y en sus posesiones ultramarinas. Una guerra para la que el país no estaba preparada ni mental, ni militarmente y que, tras diversos avatares, tendrá, como resultado final, ceder a Francia, con el tratado de paz del 22-7-1795 en Basilea, la parte oriental de la isla de Santo Domingo, primera brecha en la integridad territorial del imperio ultramarino en América. Una integridad que constituía la máxima preocupación de los gobernantes españoles, y que se había conseguido mantener intacta desde los tratados de Utrecht.

Un punto central de esta temática fue la inversión de alianzas a la que se vio obligada España a causa de los sucesos revolucionarios franceses. La muerte violenta de Luis XVI en la guillotina resolvió el dilema que se plantea-

44 Vol. II, pp. 125-168.

Mundo moderno

Hispania Sacra 55 (2003) 
ba al gobierno de Madrid, indeciso entre buscar un acomodo diplomático con la Francia revolucionaria, que no interrumpiera bruscamente los fuertes lazos entrelazados con el vecino país a lo largo del siglo XVIII, o sumarse a las potencias, que pretendían sofocar con las armas el fuego revolucionario surgido en territorio galo. Tras el luctuoso suceso, ya no era posible atender la sugerencia del representante de París, Bourgoing, de establecer entre ambos países un «pacte national», que sustituyera a los tradicionales «pactos de familia». Se imponía, a cambio, la necesidad de coordinar las operaciones navales con su tradicional rival marítimo, Inglaterra. Esto suponía una verdadera inversión de alianzas, para la que el país no estaba psicológicamente preparado. Se hacía muy cuesta arriba abandonar la tradicional alianza con el país vecino, que había ido tejiendo una tupida red de relaciones humanas y de intereses comunes, para pasar a ser aliados de una Gran Bretaña con la que se había mantenido una secular rivalidad por el dominio de los mares. No resultaba tarea fácil. Kageneck sigue atentamente este proceso lleno de dificultades, que conduce a los acuerdos hispano-ingleses del 25 de mayo de 1793. Señala los recelos y temores españoles hacia una alianza con la potencia que había sido la tradicional enemiga del imperio español; alianza que, a juicio del propio embajador, podría ser, a medio y largo plazo, poco ventajosa para España, especialmente en relación con el mantenimiento de las posesiones americanas.

Habida cuenta de este contexto anímico, no es de extrañar que, poco después de concluida esta guerra, atenuado el tremendo impacto producido por el ajusticiamiento de Luis XVI, apaciguado el radicalismo revolucionario y suscitada la esperanza de una eventual restauración monárquica en Francia, se volviera a las antiguas querencias en política exterior. Se concretan en la alianza de España con la Francia del Directorio mediante el tratado defensivo y ofensivo de San Ildefonso, el 18 de agosto de 1796. Viraje diplomático que conlleva la ruptura de relaciones con Inglaterra, preludio de una enésima guerra con esta potencia. Guerra que será de fatales consecuencias para las fuerzas navales de España y, consiguientemente, para el mantenimiento de su imperio ultramarino. Cuestiones que, evidentemente, no tienen cabida en los despachos analizados, que sólo llegan hasta finales del año 1795.

El cuadro que Kageneck nos presenta sobre el trasfondo diplomático de la guerra - conformado éste sobre el eje de la triple alianza austro-ruso- prusiana de 1792, los acuerdos de Inglaterra con Rusia y Austria en marzo y agosto de 1793, y las alianzas bilaterales establecidas por Gran Bretaña con Cerdeña, España, Nápoles-Sicilia y Portugal, a lo largo de este último año, seguidas de un tratado con Holanda en abril de 1794, lo completa con sus informaciones y comentarios sobre las suspicacias españolas hacia otros miembros de la coalición antirrevolucionaria y las dudas sobre la consistencia de la misma, así como sobre los temores a una paz separada por parte de los países implica- 
dos en la contienda. Precisamente serán España y Prusia, contra la que más recelos manifiesta el gobierno español, las que firmarán una paz unilateral en los respectivos tratados de 1795 en Basilea. Acerca de este particular, el embajador austríaco hace frecuentes referencias, a partir de julio de 1794, a los crecientes rumores sobre sondeos y negociaciones secretas entre España y Francia, que hacen presagiar una paz bilateral al margen de la gran coalición, con los efectos mencionados en párrafos anteriores. Es el propio Kageneck quien afirma categóricamente que «sólo la conclusión de la paz puede salvar a España de un desastre» ${ }^{45}$. Otro tema de política internacional, que aparece varias veces en esta correspondencia diplomática, es el reparto de Polonia, que era visto con desagrado por el gobierno español.

La crónica de la guerra, con sus avances y retrocesos en la frontera de los Pirineos, tiene puntual y amplio reflejo en los informes semanales enviados a Viena, que llenan las páginas de los tomos cuarto, quinto y sexto. Junto al relato, más o menos preciso, de las operaciones bélicas por tierra y mar, Kageneck nos da a conocer el cambiante estado de ánimo de los dirigentes españoles, desde la euforia inicial con la toma de Tolón al abatimiento final con la invasión gala del territorio español en la raya fronteriza.

En sus apreciaciones sobre la participación española en esta guerra, Kageneck, aunque partidario e impulsor de la entrada de España en la misma, reconoce que este país no contaba con los recursos militares necesarios, ni con el ánimo preciso, para afrontar una guerra del género con ciertas garantías de éxito. Comenta repetidas veces las deficiencias del ejército de tierra, la escasez de efectivos, agudizada por las enfermedades que diezmaban sus filas; los serios problemas de organización y de intendencia, que limitaban aún más su operatividad; la escasa confianza de la tropa hacia sus oficiales: una oficialidad, excesiva en número, inexperta y de escasa profesionalidad, en cuyos nombramientos y ascensos primaban más el favoritismo cortesano y el nepotismo o amiguismo ministerial que los méritos personales. A este respecto comenta, en uno de sus despachos, que «casi todos ellos han alcanzado sus puestos por el favor y no por méritos» ${ }^{46}$. En otro lugar, llega a afirmar que, «apartados los oficiales más veteranos y colocadas gentes que nunca han visto a un enemigo o participado en una campaña», resultaba difícil «designar a un oficial que sea capaz de redactar un plan de operaciones ${ }^{47}$. A su juicio, el estado

45 Despacho, $\mathrm{n}^{\circ} 32$, del 6 de agosto de 1974, V, p. 258.

46 Despachos, $\mathrm{n}^{\circ} 12$ y 37 , del 11 de marzo y de 5 de agosto de 1793 , IV, pp. 84 y 310.

47 Despacho, $\mathrm{n}^{\circ} 16$, del 1 de abril de 1793, IV, p. 116. Insistiendo en este favoritismo como criterio de selección y promoción, menciona el caso de tres hijos de un ministro, capitanes en el ejército con rango de coroneles, que tenían edades inferiores a la de su hermano, Antonio Domingo de Porlier, recién nombrado secretario de embajada en Lisboa a la edad de 21 , en despacho, $\mathrm{n}^{\circ} 58$, del 23 de diciembre de 1793, IV, p. 482. El ministro aludido era Antonio de Porlier y Sopranis, secretario de Estado y del Despacho de Gracia y Justicia (1787-1792).

Mundo moderno

Hispania Sacra 55 (2003) 
de la armada era mejor. Precisaba, no obstante, que, si bien había experimentado importantes refuerzos en los últimos tiempos y representaba un poder considerable, no era suficiente para enfrentarse, por sí sola, a cualquiera de las dos grandes potencias marítimas, Francia e Inglaterra; especialmente a la armada británica, si, en un futuro más o menos próximo, se producía el caso de un enfrentamiento con este país.

El relato de los vaivenes de la guerra, cuyo escenario son los territorios fronterizos del norte y el mar, conforma, inicialmente, el contenido principal de los informes del tomo sexto. Recogen la creciente preocupación de Kageneck por el constante deterioro de la situación militar española, que hacía presagiar el hundimiento de las defensas españolas en la raya fronteriza. El embajador deja constancia de los frecuentes reveses de las tropas españolas, acompañados de acciones heroicas de las milicias provinciales; del creciente desánimo y de los generalizados anhelos de paz. Luego, se hace eco de los insistentes rumores sobre la existencia de negociaciones de paz, que no tardan en confirmarse, hasta culminar en la firma del tratado de paz, en la ciudad suiza de Basilea, el 22 de julio de 1795. Aunque este desenlace supone un gran desencanto para el embajador austríaco, reconoce, sin embargo, que, dadas las circunstancias, era la única solución viable para el gobierno español. Llegada la paz, constata que ésta no ha servido para mejorar la situación general del país. «Los despropósitos del gobierno, en lugar de disminuir, han aumentado, al igual que las intrigas en la Corte ... La gente se queja de que no llegan los esperados frutos de la paz»: suben los precios de los alimentos, a pesar de una excelente cosecha; se devalúa el valor de los vales reales, que llega hasta el $15 \%$; en la mayoría de las ciudades portuarias desaparece el dinero efectivo; disminuyen las remuneraciones de los trabajos manuales y artesanos ${ }^{48}$. Las quejas suben de tono en el campo, ante la creciente «inseguridad de los caminos, asaltados de continuo por soldados desmilitarizados y por contrabandistas escasos de ganancias, de modo que ningún carruaje puede cruzarlos sin acompañamiento de diez o doce hombres ${ }^{49}$.

Como colofón a este recorrido por los diferentes volúmenes de la colección, cabe traer a colación ciertos textos, contenidos en la correspondencia diplomática de Kageneck, que recuerdan situaciones y fenómenos similares ocurridos en la posterior guerra de la independencia contra la invasión napoleónica y en sus prolegómenos: la fidelidad del pueblo a la monarquía y a la religión; como contrapunto, una sorda irritación de la población contra el gobierno y los escándalos de la corte, que podía estallar de un momento a otro; el papel decisivo del clero para galvanizar al pueblo contra los franceses y mantenerlo unido a la

48 Despacho, $\mathrm{n}^{\circ}$ 49, del 17 de noviembre de 1795, VI, pp. 336-337.

49 En ibidem, p. 337. 
institución monárquica; la existencia de una minoría, integrada principalmente por miembros de las profesiones liberales e intelectuales inclinados a aceptar los principios revolucionarios; el recurso a las milicias provinciales y a formas irregulares de lucha, como armar al pueblo, para suplir las limitaciones y deficiencias de las fuerzas regulares, especialmente las de tierra; una notable disociación entre una clase dirigente, que no parece estar a la altura de la crítica situación, y un pueblo llano, que demuestra estarlo, con su capacidad de sacrificio, de lucha, de improvisación y de resistencia ante las adversidades.

Son muchas las citas que podrían espigarse sobre el particular. Aparte de las ya reseñadas, baste mencionar algunas más, como botón de muestra. A la altura del mes de agosto de 1794, al informar sobre la situación cada vez más difícil que atravesaba el país, abatido por los continuos reveses militares e irritado por los escándalos de la corte, comentaba que, pese a ello y al creciente descontento contra el gobierno del valido Godoy, «el clero y el campesinado mantenían intactos su afecto y adhesión a la religión y al rey» $\rangle^{50}$. No menos rotundo se muestra acerca de la influencia de la Iglesia en el rearme moral y mental del pueblo: «el clero expande incansablemente por toda España el odio contra los franceses; la actual temporada de Cuaresma proporciona una excelente ocasión para ello, y en las calles y plazas de todas las ciudades y pueblos se escucha a los predicadores y misioneros, que se esmeran por hacer comprender al pueblo los peligros que encierran los principios de la revolución francesa. La exacerbación ha alcanzado tales extremos que se hace preciso contener al pueblo, para que no descargue todo su furor sobre los residentes franceses ${ }^{51}$. En cuanto a la existencia de una minoría simpatizante con los presupuestos ideológicos de la revolución francesa, que Kageneck asocia a la figura del conde de Aranda, y que no ve con buenos ojos, se expresa del siguiente modo: «El estado de ánimo de la mayor parte de la nación es bueno; ésta, excitada sobre todo por el clero, está muy exacerbada contra los franceses. No obstante, se detectan demasiados partidarios del nuevo sistema francés y aquí, como en casi todas partes, se descubre que, no sólo los abogados, sino la mayoría de los llamados 'civiles' están infectados por el veneno de la innovación» ${ }^{52}$.

50 Despacho, $\mathrm{n}^{\circ} 32$, del 5 de agosto de $1794, \mathrm{~V}, \mathrm{p}$. 258. A continuación añade que no podía decirse lo mismo de la nobleza y algunos sectores de la población urbana.

51 Despacho, $\mathrm{n}^{\circ} 12$, del 11 de mayo de 1793, IV, p. 82. En posteriores despachos recoge algunos de estos casos, como lo ocurrido al diplomático francés Bourgoing, cuando se dirigía a su país con su familia, y a un enviado galo a Portugal, Darbaut, en el despacho, $\mathrm{n}^{\circ} 14$, del día 18, ibidem, pp. 97-98. También en este despacho y varios despachos más, $\mathrm{n}^{\circ} 12,16,17$, del 11 de marzo y del 1 y 8 de abril, ibidem, pp. 88, 121-122, 123 y 134, se hace eco de lo ocurrido en Valencia. En la urbe levantina los ataques a los franceses se prolongaron del 27 de febrero al 26 de marzo de 1793, según narra Vicente Boix Ricarte en su Historia de la ciudad y reino de Valencia, tomo 2, Valencia: Imprenta de Benito Monfort, 1845, pp. 109-114; de esta obra existen reediciones posteriores en facsímil, Valencia: Albatros, 1979 y 1988.

52 Despacho, $\mathrm{n}^{\circ} 20$, del 22 de abril de 1793, IV, p. 148.

Mundo moderno

Hispania Sacra 55 (2003) 
Tras el hundimiento del frente español en el Rosellón y la entrada de tropas francesas en España, Kageneck destaca, una y otra vez, el decisivo papel jugado por las respectivas milicias provinciales y el campesinado, como en el caso de los somatenes catalanes. Estos hacen gala de una indomable voluntad de resistencia en defensa del territorio invadido y una gran capacidad de maniobra: «muestran - dice - una gran decisión y son animados por los clérigos a luchar contra el enemigo». Añade que entre sus mandos se encontraban miembros del clero secular y regular, como el canónigo de Gerona, Martín Cuffi, o el franciscano Cosme Busch, que contaban con la oportuna autorización de la Nunciatura ${ }^{53}$. En el mismo despacho, nuestro diplomático refiere que se habían producido varias escaramuzas fronterizas, «en las que los montañeses catalanes, dirigidos por funcionarios y clérigos, han demostrado una gran resolución para defender su país y han infligido un duro golpe al enemigo», causándole, en uno de los enfrentamientos, ocurrido el 4 de junio en el Col de Pendía, 45 muertos y cogiendo varios prisioneros ${ }^{54}$.

Son situaciones que guardan notable similitud con las ocurridas años más tarde, cuando se produce la lucha de guerrillas contra la intervención napoleónica en España. Nos encontramos, pues, con claros antecedentes de los episodios y de las soluciones dadas por los españoles para hacer frente a la quiebra de la monarquía tradicional y al colapso del ejército regular a raíz de la instauración de la dinastía Bonaparte en España. Cabe concluir, por tanto, que las aludidas soluciones no surgieron por generación espontánea. Ya se habían ensayado anteriormente; y no fueron tan improvisadas como se ha querido dar a entender por la historiografía al uso.

El propio motín de Aranjuez, que abre camino al posterior período de guerra y revolución en España, vendría a hacer realidad lo que el embajador Kageneck había presentido. Una y otra vez había advertido a Viena de la existencia de factores, que podían provocar un levantamiento popular en España: una creciente animosidad contra una clase gobernante y un aparato administrativo, presa de la corrupción, el amiguismo o el nepotismo, e irritación contra los escándalos e intrigas de la Corte. Efervescencia popular que, si aún no ha dado lugar a una revuelta, se debe, anota Kageneck, «únicamente al amor del pueblo hacia la persona del rey, a la influencia del clero para mantener este sentimiento, $\mathrm{y}$ al natural pacífico del común de las gentes ${ }^{55}$.

53 Despacho, $\mathrm{n}^{\circ}$ 25, del 18 de junio de 1794, V, pp. 207-208. El primero de ellos se distinguirá en varias acciones posteriores, como la ocurrida en el ataque a los franceses en Ripio, en despacho, $\mathrm{n}^{\circ} 27$, del 2 de julio, ibidem, pp. 221-22.

54 En ibidem, p. 209.

55 En despacho, $\mathrm{n}^{\circ} 1$, del 6 de enero de 1795, VI, p.5. 
Pero podía producirse en cualquier momento. A la altura del mes de agosto de 1793, el embajador vienés formulaba un pronóstico poco esperanzador para la estabilidad interna de la monarquía. A la vista de la marcha poco satisfactoria de la guerra contra Francia, causa de nuevas quejas contra la acción del gobierno, advertía, con preocupación, que, si bien «el común de las gentes se muestra, de modo generalizado, contrario a los franceses, aunque mayoritariamente sólo por consideraciones religiosas, - sin embargo-, entre una gran parte de ellos, se observa fuerte animosidad contra la Corte y contra el Gobierno, que tendrá, más pronto o más tarde, graves consecuencias» ${ }^{56}$. No era la primera vez que avisaba del peligro latente de un levantamiento, cuyos perfiles no acababa de precisar. Ni será la última. Algo más tarde, iniciado el año 1795, volvía a la carga, para matizar el alcance, que pudiera tener el presagiado levantamiento popular, que, «por parte de la mayoría no iría contra el Rey, sino contra el ministro» ${ }^{57}$, es decir contra el valido Godoy. Toda una premonición de lo que ocurrirá años más tarde en Aranjuez

Pero el descontento del pueblo, largamente incubado y mantenido en sordina por el clero, estalla furioso en la noche del 17 de marzo de 1808 y se prolonga hasta la tarde del día 19. Supuso la caída del valido, Manuel de Godoy, y desencadenó una aguda crisis dinástica, que trajo la intronización de Fernando VII en sustitución de su padre, Carlos IV. Ese movimiento popular, una vez desencadenado, se extiende, posteriormente, de modo irresistible, por todo el país, para hacer frente a la intervención de Napoleón I en aquel pleito familiar, que él aprovecha para asumir personalmente la corona española y cederla, poco después, a su hermano José Bonaparte.

En otro orden de cosas, las apreciaciones de Kageneck dejan entrever, en el campo de las mentalidades, una población mayoritariamente aferrada a las tradiciones y creencias católicas, y una reducida minoría abierta a las ideas derivadas de la Ilustración e impuestas por la revolución de allende el Pirineo $^{58}$. Una minoría, con escasa capacidad de convocatoria - a diferencia de lo que ocurría con el clero- entre el pueblo llano y aún menos entre el campesinado. Y que será aventada al concluir la guerra de la independencia, acusada de colaboracionista con los invasores o de simpatizante con sus ideas, produciendo una gran fractura mental en el país, con funestas consecuencias para la dinámica histórica de la España contemporánea.

56 En despacho, $\mathrm{n}^{\circ}$ 39, del 19 de agosto de 1793, IV, p. 328.

57 En despacho, $n^{\circ} 1$, del 6 de enero de 1795, VI, pp.56-6-

58 Muy recientemente han salido a luz dos obras, que se ocupan del mundo de las ideas en aquella época, particularmente con referencia al campo de la política: Francisco SÁNCHEZ-BLANCO, El absolutismo y las luces en el reinado de Carlos III, Madrid: Marcial Pons, 2002; y Mario ONAINDÍA, La construcción de la nación española. Republicanismo y nacionalismo en la Ilustración, Barcelona: Ediciones B, 2002.

Mundo moderno

Hispania Sacra 55 (2003) 
Estas similitudes o coincidencias refuerzan la idea, que compartimos muchos, de que es preciso ahondar aún más en el conocimiento del reinado de Carlos IV y de aquella sociedad española. Nos ayudará a dilucidar en toda su complejidad, y a desentrañar en sus raíces más profundas, los acontecimientos que marcaron los inicios de la edad contemporánea española, y dieron lugar al desmantelamiento del Antiguo Régimen en España.

Para esta tarea, la correspondencia diplomática contenida en los seis volúmenes, que aquí se presentan, proporciona un nuevo e importante instrumento de análisis. En ellos, el investigador o el lector curioso encontrará una amplia información, no sólo sobre la acción exterior de aquel reinado, sino también sobre la política interior de Carlos IV y sus ministros. Le proporcionará datos y observaciones sobre las realidades de España y sus dominios ultramarinos: instituciones políticas y élites de poder; sus tierras y hombres; sus usos y costumbres, su religiosidad; sus estructuras económicas y comerciales; su organización administrativa, sus recursos militares de mar y tierra; grupos políticos y poderes fácticos. Se echan de menos, en cambio, referencias al mundo de las letras, del arte o de la ciencia. Volcado en el análisis de la situación militar, política y social de la monarquía hispana, ante la que estaba acreditado desde 1786, Juan Federico, conde Kageneck, no tuvo tiempo para ocuparse de cuestiones culturales o científicas. Sirven de excepciones a la regla, en estas materias, lo expuesto anteriormente sobre las explotaciones mineras ${ }^{59}$, y unas breves referencias a la expedición naval con fines científicos encomendada a Alejandro Malaspina ${ }^{60}$.

59 Ver nota 15.

60 En los despachos, no 19 y 29, del 4 de mayo y del 14 de julio de 1789, I, pp. 132-133 y $179-$ 180; y en el $\mathrm{n}^{\circ} 52$, del 8 diciembre de 1795, VI, 361 y 362. Este personaje, su expedición científica y sus andanzas políticas, han sido objeto de varios estudios en los últimos tiempos: M. D. HIGUERAS, Catálogo crítico de los documentos de la Expedición Malaspina (1789-1794), Madrid: Museo Naval,1985; Emilio SOLER PASCUAL, Antagonismo político en la España de Godoy: la conspiración Malaspina, 1795-1796, Alicante: Instituto de Cultura «Juan Gil-Albert», 1990; del mismo autor, La aventura de Malaspina, Barcelona: Ediciones B, 1999, donde narra las peripecias del marino italiano al servicio de la Corona española a bordo de la Descubierta y la Atrevida, así como su naufragio en las intrigas de la Corte; Eric BEERMAN, El diario del proceso y encarcelamiento de Alejandro Malaspina, 1794-1803, Madrid: Editora Naval, 1992; Juan PIMENTEL, La fisica de la monarquía. Ciencia y politica en el pensamiento colonial de Alejandro Malaspina (1754-1810), Aranjuez: Doce Calles, 1998. El tema de las expediciones navales, con misiones científicas, realizadas en el siglo XVIII, está de moda en la actual historiografía española. Una muestra de ello son las páginas que acaba de dedicar al mismo el Blanco y Negro Cultural de $A B C$, Núm. 571, del 4 de enero de 2003, pp. 4-9, bajo el epígrafe «La España de las expediciones», uno de cuyos apartados contiene varias referencias bibliográficas de obras recientes. A los títulos allí referidos podría añadirse el de Antonio MENCHACA, La Rosa de los Vientos: el explorador y navegante Bodega Cuadra, Madrid: Biblioteca Nueva, 2000, donde ofrece una semblanza biográfica de este marino (1744-1794) nacido en Lima, y de su participación en las expediciones, exploraciones y descubrimientos en las costas del Pacífico Norte americano. 
No aparecen, por ejemplo, nombres tan significativos, como el de Jovellanos, todavía activo, - sí el de Campomanes ( $† 1802)$, ya en el declinar de su vida-; tampoco el de Goya, pintor de cámara desde abril de 1789 y en plena carrera ascendente, o el de su colega Maella; o los de los fallecidos Mayáns y Feijóo. Sí lo había hecho abundantemente su antecesor, Pietro Paolo Giusti. Éste, entre 1773 y 1781, se ocupó, repetidas veces, de informar sobre el desarrollo de las ciencias, las artes y las letras en España. Algunos de sus informes al respecto constituyen verdaderos ensayos acerca de la historia y de la cultura española ${ }^{61}$.

Una buena guía para localizar cómodamente los temas o personajes deseados son los índices onomástico y de materias. Un repaso a los mismos permite observar la variedad de cuestiones, que se abordan en la correspondencia enviada por Kageneck a Viena. Junto a los mencionados índices -el de materias, en alemán y español-, deben destacarse las numerosas notas, 1608 para los seis volúmenes, que ilustran los textos de los despachos diplomáticos. Aportan una información suplementaria, sobre hechos y personajes, del mayor interés para la mejor comprensión de los textos transcritos. En bastantes casos representan una verdadera puesta al día del estado de la cuestión, objeto de la nota. En algunas, pocas, se incluye el texto de las instrucciones impartidas a Kageneck desde Viena. Al apartado de notas sigue, en cada volumen, una relación de fuentes impresas y de bibliografía, que han servido de base al autor para la redacción de dichas notas; debe señalarse que los nombres mencionados en dicha relación no se recogen en los referidos índices. A las indicadas relaciones bibliográficas cabría añadir varios títulos, algunos de muy reciente aparición, que tratan temas con amplia presencia en estos seis volúmenes, como las obras, monográficas o de carácter general, de Anes, Aymes, Castro, Egido, García Cárcel, Iglesias, Roura, y otros ${ }^{62}$. Con ello se intentaría, en la medida de lo posible, subsanar

61 En los vols. XII y XIII de la colección citada en nota 2.

62 Jean René AYMES (editor), España y la Revolución Francesa, Barcelona: Crítica, 1989; del mismo autor, La guerra de España contra la Revolución Francesa, Alicante: Instituto de Cultura «Juan Gil-Albert», 1991. Michel CADÉ, Guerre et Révolution en Rousillon, 1793-1795, Perpignan: Direction des Services d'Archives, 1990. Concepción de CASTRO, Campomanes. Estado y reformismo ilustrado, Madrid: Alianza Editorial, 1996; con motivo del bicentenario de su muerte, la pertinenete Comisión Nacional organiza diversos actos culturales, de los que destaca una exposición, Campomanes y su tiempo, que se propone revivir el ambiente de cambios y reformas en la segunda mitad del siglo XVIII, de los que el asturiano Pedro Rodríguez de Campomanes fue una de las figuras más representativas. Juan HERNÁNDEZ FRANCO, Aspectos de la política exterior de España en la época de Floridablanca, Murcia: Real Academia Alfonso X el Sabio, 1992., Alfredo MARTínez AlBIACH Religiosidad hispana y sociedad borbónica, Burgos: Facultad Teológica del Norte de España, 1969. Gérard DOFOUR y Emilio LA PARRA (presentación), «Guerra de la Convención. Informe»; con varios trabajos, en Studia Historica. Historia Moderna, Salamanca:Universidad, 12 (1994) 13-112. Lluís RoURA AULINAS, Guerra Gran a la ratlla de Francia: Catalunya dins la guerra contra la Revolució Frances (1793-1705), Barcelona: Editorial Curial, 1993. Teófanes EgIDO, Carlos IV, Madrid: Arlanza, 2001. Ma . Luisa LóPEZ-VIDRIERO, Specvlvm Principvm, Madrid: Biblioteca Nueva / Instituto de Historia del

Mundo moderno

Hispania Sacra 55 (2003) 
ciertas lagunas observadas en los respectivos apartados de fuentes y bibliografia; precisar algunas fichas bibliográficas deficientes o demasiado sucintas; $y$, sobre todo, añadir obras significativas, concernientes a temas y personas relacionados con aquel reinado, que han visto la luz con posteridad a la publicación de los volúmenes, objeto de nuestra atención. Esta labor complementaria se realiza en la adjunta nota bibliográfica y en otras anteriores y posteriores del mismo tenor, que se insertan a pie de página a lo largo del presente trabajo. De este modo, se pretende ofrecer a los lectores una primera aproximación a la bibliografía acerca de aquella época, de sus problemas, de sus realizaciones en múltiples aspectos del quehacer histórico, y de sus protagonistas.

Otro elemento, que facilita la labor de conocer el contenido esencial de cada uno de los informes publicados, son los resúmenes de los mismos, redacta-

\begin{abstract}
Libro y de la Lectura, 2002, donde, a vueltas con el contenido de la biblioteca del príncipe Carlos Antonio de Borbón, aún Príncipe de Asturias, diserta sobre sus preceptores y sobre el ambiente cultural de la Corte. De carácter más general pueden mencionarse: Gonzalo ANES, El siglo de las luces, Madrid: Alianza Editorial, 1994, donde analiza, desde una perspectiva social, económica y política, tanto interior como exterior, los reinados de los cuatro Borbones del siglo XVIII; es una nueva reescritura del volumen IV de la Historia de España dirigida por Miguel Artola, que se titulaba Los Borbones, Madrid: Alfaguara, 1975; el mismo Anes, como Director de la Real Academia de la Historia, abría en febrero de este año de 2002, un ciclo de conferencias, en la Fundación Santander Central Hispano, dedicado a «El fin del Antiguo Régimen». La obra colectiva dirigida por Agustín GUIMERÁ (editor), El reformismo borbónico, Madrid: Alianza Editorial, 1996, donde se hace un balance actualizado de esta temática. Más reciente aún, la coordinada por Ricardo GARCÍA CÁRCEL (coord..), Historia de España siglo XVIII. La España de los Borbones, Madrid: Cátedra, 2002, donde varios autores nos ofrecen una historia política de cada reinado y una cumplida síntesis de los aspectos socio-económicos, culturales y científico-técnicos de la época. Carmen IGLESIAS (ed.), Ilustración y proyecto liberal. La lucha contra la pobreza, Zaragoza: Ibercaja, 2001, es una obra explicativa y analítica de la exposición realizada el mismo año en Zaragoza; en ella colaboran varios autores, que abordan el fenómeno de la pobreza en la España de la Ilustración y del incipiente liberalismo, así como de las distintas iniciativas emprendidas para buscarle soluciones. Para una visión de conjunto del contexto económico y social de la época, con una bien abastecida bibliografía, puede ser útil la voluminosa obra de Alberto MARCOS MARTín, España en los siglos XVI, XVII y XVIII. Economía y sociedad, Barcelona: Editorial Crítica, 2000. En cuanto a obras más antiguas, se mencionan aquellas que atañen directamente a la guerra entre España y la Francia revolucionaria y no aparecen recogidas en las aludidas relaciones bibliográficas de los respectivos volúmenes: Campañas de los Pirineos a finales del siglo XVIII, 1793-1795, Madrid: Estado Mayor del Ejército / Servicio Histórico Militar, 1949-1954, 4 vols.; Fermín de LASALA Y COLLADO, La separación de Guipúzcoa y la paz de Basilea, Madrid: Fontanet, 1895; Francisco HERNÁNDEZ SANZ, Episodios de la guerra de los angloespañoles contra Francia durante la primera república, vistos desde Mahón, 1793-1795, Mahón: Tipografia Mahonesa, 1933. Para el reinado de Carlos IV: Juan PÉREZ GuZMÁN Y GALLO, Estudios de la vida y reinado, prescripción y muerte de D. Carlos y María Luisa de Borbón, reyes de España, Madrid: Imprenta de J. Ratés Martín, 1908, con una $2^{\mathrm{a}}$ edición al año siguiente; es autor de otros estudios, uno sobre Las relaciones politicas de España con las demás potencias de Europa al caer el Conde de Floridablanca en 1792, Madrid, 1906, separata de la Revista de Derecho Internacional y Política Exterior, y otro (un discurso) sobre La embajada del Conde Fernán-Núñez en París durante el primer periodo de la Revolución Francesa, Madrid, 1907. Cabe añadir que la obra de Hans-Roger MADOL, citada en su versión alemana, tiene traducción en español: Godoy, Madrid: Alianza Editorial, 1966.
\end{abstract}


dos en alemán y español; preceden a los índices de materias y de nombres. En este aparato crítico, ejemplar por tantos conceptos, se echa en falta que no hayan sido transcritos todos los apéndices documentales, que habitualmente acompañan a los despachos. Su presencia habría enriquecido aún más la ya de por sí abundantísima información contenida en esta colección. Sí se hace con algunos, pero no con la mayoría, limitándose a indicar su localización en los fondos archivísticos, donde se conservan. Se trata de una documentación de carácter muy variado, complementaria de los temas expuestos en los respectivos despachos. Desde 1793 predominan los concernientes al desarrollo de la guerra en la raya fronteriza: diarios de las operaciones o informes diversos procedentes de los escenarios de la contienda. Probablemente se ha optado por prescindir de muchos de ellos - plausible en el caso de los recortes o números de La Gaceta de Madrid - , para no agrandar excesivamente los volúmenes, ni encarecer su publicación.

Todos estos volúmenes tienen una estructura muy similar, con pequeñas variantes en algunos de ellos. Cada volumen se inicia con una breve, pero enjundiosa, introducción, bilingüe, del director y editor de la serie, el profesor Hans Juretschke, donde se trazan las grandes líneas del contenido. En el primero de los volúmenes se añade una segunda introducción de Hans-Otto Kleinmann, también bilingüe, sobre las relaciones hispano-austríacas durante el período revolucionario. Lo mismo ocurre en el volumen sexto sobre dichas relaciones a caballo entre los siglos XVIII y XIX. Siguen las observaciones técnicas relativas a la edición de los textos con indicación de las abreviaturas y siglas utilizadas, sólo en alemán. Viene, luego, el grueso del volumen con la trascripción de los despachos, redactados en alemán, mientras que los documentos anejos suelen estar en español o francés. A continuación se añaden los apartados, ya indicados, referentes a las notas, a las fuentes y bibliografía, a los resúmenes de los despachos —en alemán y español- y a los índices, el de materias en alemán y español. Los tres últimos volúmenes incluyen, además, dos breves apartados, situados inmediatamente después de los despachos, con los nombres de los Secretarios de Estado españoles en activo y los nombres de los miembros del cuerpo diplomático acreditados en Madrid. Todo este aparato crítico pone de manifiesto el rigor científico y la escrupulosidad académica con que han llevado a cabo su tarea los responsables de esta colección documental: el mencionado profesor Juretschke, que, en su calidad de director del Instituto Germano-Español de Investigación de la Sociedad Görres, dirige el pertinente proyecto de investigación ${ }^{63}$; y el profesor Kleinmann, encargado de la trascripción y anotación de los textos.

63 Sobre este destacado hispanista alemán, afincado desde hace muchos años en Madrid, acaba de aparecer una voluminosa obra, VEGA, Miguel Ángel (coord..), España y Europa. Estudios de crítica

Mundo moderno

Hispania Sacra 55 (2003) 
Con esta nueva aportación, dicha Institución, que ha pasado a denominarse Fundación Alemana de Madrid, prosigue su encomiable tarea de proporcionar fuentes para el estudio de la historia de España en una época, entre los siglos XVIII y XIX, que trajo grandes convulsiones a todos los países europeos, incluida la Península Ibérica, como consecuencia de la revolución francesa de 1789 y del posterior período napoleónico. Junto con la anterior colección de 14 volúmenes, dedicada al reinado de Carlos III, forma un rico acervo de datos, apreciaciones y comentarios sobre el estado de la monarquía hispana en sus aspectos institucionales, políticos, sociales, económicos, administrativos, religiosos, militares, relaciones internacionales, intereses geopolíticos y, en menor medida, culturales, durante la segunda mitad del siglo XVIII. Su consulta y utilización pueden contribuir a enriquecer la temática y ampliar los enfoques de la historiografía sobre aquella etapa de nuestra historia.

Son bien conocidas las limitaciones de este tipo de fuentes por lo apresurado de muchos de los juicios emitidos y por la subjetividad, inherente a los mismos, derivada de los esquemas mentales previos del observador extranjero, sea éste diplomático o viajero. Limitaciones acentuadas a veces, como en el caso del embajador Kageneck, por su escaso conocimiento del español, que reducía sus fuentes de información y su capacidad de comunicación, constreñida al uso del francés, aunque de manera muy limitada. Él mismo alude a estas dificultades de comunicación con el Duque de la Alcudia y Príncipe de la Paz. De ahí que, en alguna ocasión, planteara al ministro español «la conveniencia que asistiese a nuestra entrevista una persona conocedora de la lengua francesa» ${ }^{64}$. Estas fuentes tienen, en cambio, la ventaja de ofrecernos una visión de las cosas, de los hechos y de las personas más desapasionada al contemplarlos desde una perspectiva más amplia, menos narcisista. Las salvedades apuntadas no son óbice para saludar con satisfacción la publicación de esta serie de volúmenes, que representan una aportación documental de primer orden y de obligada consulta para cuantos investigadores quieran profundizar en el conocimiento de un reinado, como el de Carlos IV, durante el cual se acumulan los elementos, que harán saltar en mil pedazos la monarquía hispana, tanto en ultramar, como en la propia metrópoli, a lo largo de las primeras décadas del siglo XIX.

cultural. Obras completas de Hans Juretschke, Madrid: Universidad Complutense, 2001, 3 vols. Cerrada ya la redacción de este trabajo, me llega la noticia de que el profesor alemán Odilo Engels ha pronunciado una conferencia sobre «La historia de la sociedad Görres y su contribución a la cultura española y a la sociedad de Madrid», en la Facultad de Teología «San Dámaso» de Madrid, el 20 de febrero de 2003.

64 Despacho, $\mathrm{n}^{\circ} 50$, del 28 de octubre de 1793, IV, p. 417. Este mismo problema era percibido por su colega inglés, en despacho, $\mathrm{n}^{\circ} 27$, del 27 de mayo del mismo año, en ibidem, p. 197. 
Viene a sumarse a otras conocidas fuentes diplomáticas o políticas, concernientes a aquel período y aquella época: los ya mencionados despachos de Sandoz-Rollin, ministro plenipotenciario de Prusia en Madrid, entre 1784 y 1795, profusamente utilizados y parcialmente reproducidos por Hermann Baumgarten en su Historia de España durante la revolución francesa ${ }^{65}$; los del ministro danés, Herman de Schubart ${ }^{66}$; o los correspondientes a los diplomáticos galos ${ }^{67}$; las Memorias de Godoy ${ }^{68}$, y los documentos contenidos en la clásica Historia de Carlos $I V$ de Andrés Muriel ${ }^{69}$; los documentos de procedencia rusa publicados por Olga Volosiuk ${ }^{70}$; los contenidos en la colección diplomática hispano-rusa ${ }^{71}$; o los despachos e instrucciones de los embajadores genoveses en España ${ }^{72}$; sin olvidar la correspondencia de los diplomáticos españoles en aquella ciudad italiana ${ }^{73}$.

También deben tenerse presentes las colecciones dedicadas a recoger los escritos de personajes que jugaron papel destacado en la vida pública española de la época, como la edición de las Obras Completas de Jovellanos, iniciada en 1984 por José Miguel Caso González, de la Universidad de Oviedo ${ }^{74}$; o la

65 Ver nota 11.

66 E. GIGAS, «Letras d'un diplomate danois en Espagne (1798-1800)», en Revue Hispanique, Paris/New York: Hispanic Society of America, 9 (1902) 393-406.

67 A las obras citadas en la nota 12 habría que añadir: A. MOREL-FATIO, y H. LEONARDON (editores), Recueil des instructions donées aux ambassadeurs et ministres de France depuis les traites de Westphalie jusqu'à la Reévolution française, tome XIIIbis, Espagne (1722-1793), Paris: Alcan,1899.

68 Manuel Godoy, Cuenta dada de su vida política por Don --------- Príncipe de la Paz; o sean Memorias críticas y apologéticas para la historia del reinado del señor D. Carlos IV de Borbón, Madrid: Imprenta de I. Sancha, 1836-1839, 6 vols.; reeditadas con estudio preliminar por Carlos SECO SERRANO, en Biblioteca de Autores Españoles, vols. 88-89, Madrid: Atlas, 1956. Hay otra edición de estas Memorias, anotadas y comentadas por Ivan PETERS, Madrid: Est. Tip. del Fomento Naval, 1908.

69 En la serie Memorial Histórico Español, colección de documentos, opúsculos y antigüedades de la Real Academia de la Historia, vols. 29 al 34, Madrid: Imprenta M. Tello, 1893, con prólogo de Menéndez Pelayo; reeditada por Carlos SECO SERRANO, en la Biblioteca de Autores Españoles, vols. 114-115, Madrid: Atlas, 1959.

70 «Jovellanos y Rusia», en Hispania, Madrid: CSIC, 48 (1988) 317-333; «La correspondencia de Catalina II y Floridablanca relacionada con la revolución francesa, septiembre de 1791 -febrero de 1792», en ibidem, 50 (1990) 303-326.

71 Manuel ESPADAS BURGOS (editor), Corpus diplomático hispano-ruso (1667-1799), Madrid: Ministerio de Asuntos Exteriores, 1991.

72 Rafaele CIASCA, Istruzioni e relazioni degli ambasciatori genovesi, vol 7, Spagna (17451797), Roma: Istituto Storico Italiano per l'Età Moderna e contemporánea, 1968.

73 SALINAS SALINAS, Carlos, «Notas sobre la República de Génova y la revolución Francesa, según la correspondencia de los embajadores españoles en Génova», en Hispania, Madrid: CSIC, 42 (1982) 173-182.

74 José M. Caso es también autor de una biografía póstuma, Jovellanos, Madrid: Ariel, 1998; en ella su hija, Teresa Caso, recopila la semblanza biográfica del ilustre personaje asturiano de la Ilustración esbozada en varios escritos por su padre.

Mundo moderno

Hispania Sacra 55 (2003) 
reciente antología de los escritos de Alejandro Malaspina ${ }^{75}$, a cuya expedición marítima alude Kageneck en cuatro ocasiones ${ }^{76}$; así como las también recientes publicaciones de escritos de Betancourt (1758-1824), de Llorente (17561823) y del propio Jovellanos (1744-1811), sobre el desarrollo de la ciencia y de la técnica, en el primer caso, los intentos de reforma del tribunal de la Inquisición, en el segundo, y la reforma agraria, en el tercero ${ }^{77}$.

Sobre otro aspecto característico de la época, los proyectos de grandiosas obras públicas de canales y vías de comunicación, cabe citar una obra, basada en documentación original - memoria y planos-, dedicada a la presa de Gasco, en el río Guadarrama, cabecera de un ambicioso, más bien quimérico, proyecto de un canal navegable, Madrid-Sevilla, hasta el $\operatorname{mar}^{78}$. Por otro lado, al conmemorarse, en la pasada década, los 250 años del nacimiento de Francisco de Paula José de Goya y Lucientes (1746-1828) dio lugar a la celebración de

75 La edición de la antología ha sido realizada por Blanca Sáiz, Madrid, 1995, en la que, entre otros, se recogen sus textos políticos.

76 Vol. I, pp. 130-131, 179-180; vol. V, p. 338; y vol. VI, pp.361-362.

77 Agustín de Betancourt y Molina, Memorias de las Reales Minas del Alamdén. Edición, nota biográfica, estudio introductorio, trascripción, notas y glosario de términos por Ignacio González Tascón y Joaquín Fernández Pérez, Madrid: Comisión Interministerial de Ciencia y Tecnología, 1990. En la primavera de 1996 se presentó, en el Real Jardín Botánico de Madrid, una exposición titulada Betancourt. Los inicios de la ingeniería moderna en Europa. No en vano, este personaje fue promotor de varias instituciones en pro de la ciencia y de la técnica, inventor de varios ingenios, que se dedicó al espionaje industrial en Inglaterra y Francia, y que estuvo al servicio de los zares en los últimos 16 años de su vida. Juan Antonio LlORENTE, Discursos sobre el orden de procesar en los tribunales de la Inquisición, una memoria, para la reforma del Tribunal inquisitorial, elaborada inicialmente en 1793, a petición del inquisidor general, Agustín Abbad y Lasierra, y completada en 1797; la edición crítica de este manuscrito corrió a cargo de Enrique de la Lama López Areal, Pamplona: Eunate, 1995. Sobre Jovellanos son varias las publicaciones que han aparecido en estos últimos años: VV.AA., La agricultura española. De Jovellanos a la Unión Europea, Madrid: Ministerio de Agricultura, Pesca y Alimentación, 1996; obra de varios autores en 3 vols., publicada para conmemorar el segundo centenario del célebre Informe en el expediente de Ley Agraria para la real Sociedad Económica Matritense de Amigos del País, cuyo facsímil se recoge en el primero de los tres volúmenes; los otros dos volúmenes están dedicados a las políticas y reformas agrarias en la historia de España, y a la modernización y cambios estructurales operados últimamente en la agricultura española. Poco antes aparecía un estudio acerca de la reforma agraria en la época de los Borbones dieciochescos, obra de Gonzalo ANES, La Ley Agraria, Madrid: Alianza Editorial, 1995. Aparte de la biografia de Jovellanos, escrita por J.M. Caso, citada en nota 74, aún cabe añadir otras dos más recientes: Manuel FERNÁNDEZ ÁLVAREZ, Jovellanos, el patriota, Madrid: Espasa, 2001; y ÁlVAREZ-VALDÉS Y VALDÉs, Jovellanos: enigmas y certezas, Gijón: Fundación Alvargonzález/Fundación Foro Jovellanos del Principado de Asturias, 2002, con un prólogo de Gonzalo Anes.

78 Teresa SÁNCHEZ LÁZARO, Carlos Lamaur y el canal de Guadarrama, Madrid: Colegio de Ingenieros de Caminos, Canales y Puertos, 1995. Un reportaje sobre este libro, y sobre la construcción de la que se ocupa, puede verse en el periódico El País, del 12 de mayo de 1996, en la sección «Madrid», pp. 1 y $4-5$. 
numerosos actos culturales y a diversas publicaciones en torno a esta figura y al mundo del arte y de la cultura de su época ${ }^{79}$.

A las fuentes mencionadas, cabría añadir las descripciones sobre la realidad española del momento hechas por observadores y viajeros extranjeros entre los siglos XVIII y XIX. Es el caso del citado J.-F. Bourgoing ${ }^{80}$, de su compatriota A. de Laborde ${ }^{81}$; del clérigo británico J. Townsend ${ }^{82}$; de los alemanes L.A. Kaufhold, Ch. A. Fischer, W. von Humboldt, H. F. Link, para la península ${ }^{83}$, y

79 Cabe mencionar, por ejemplo, la edición en español, revisada y ampliada, de la obra de Jeannine BATICLE, Goya, Barcelona: Crítica, 1996; posteriormente, ha aparecido un estudio sobre el pintor de Fuendetodos desde la perspectiva de un psiquiatra, el catedrático de Psiquiatría y Psicología Médica de la UCM, Francisco AlONSO-FERnÁNDEZ, El enigma Goya, México: Fondo de Cultura Económica, 1999; más recientemente, ha salido a luz una publicación colectiva, en la que participan 20 especialistas, que analizan la obra del pintor y el contexto histórico, social y artístico, que le rodea: Goya, Madrid: Fundación Amigos del Museo del Prado y el Círculo de Lectores/Galaxia Gutenberg, 2001. Similares características, en cuanto a contenido y enfoque, reúne un estudio sobre el músico italiano L. Boccherini (1743-1805), afincado en Madrid desde 1768: Jaime TORTELLA, Boccherini. Un músico italiano en la España ilustrada, Madrid: Sociedad Española de Musicología, 2002. Otro destacado pintor de la época, Maella (1739-1819), cuenta, igualmente, con una reciente biografia: José Luis MORALES MARÍN, Mariano Salvador Maella. Vida y obra, Zaragoza: Moncayo, 1996. En cuanto a la faceta literaria de la cultura, podría citarse una obra general, iniciada en 1995, sobre la Historia de la Literatura Española, dirigida por Victor GARCÍA DE LA CONCHA, y coordinada por Guillermo CARNERO, cuya primera entrega, de las doce previstas, está dedicada al siglo XVIII, Madrid: Espasa-Calpe, 1995, 2 vols.

80 Ver nota 10.

81 Alexandre de LABORDE, Itinéraire descriptif de l'Espagne, et Tableau élémentaire des diferentes branches de l'administration et de l'industrie de ce rayaume, Paris: $\mathrm{H}$. Nicolle, 1808, 6 vols., con varias ediciones posteriores y traducciones al español, alemán y al inglés; es autor, también, de un Voyage pittoresque et historique de l'Espagne par ---------ot una societé de gens de lettres de Madrid ..., Paris: Impr. de P. Didot l'ainé, 1806-1820, 2 vols.., cuenta con traducción al español.

82 Fue publicada en 1791, pero se refiere a un viaje realizado a España entre 1786 y 1787: Joseph TOWNSEND, A journey through Spain in the years 1786 and 1787, with particular attention to the agriculture, manufactures, comerce, population, taxes and revenue of that country and remarks passing through a part of France, London: C. Dilly, 1791, 3 vols., con reediciones posteriores y traducciones coetáneas al alemán, francés y holandés; en 1988, Madrid: Turner, se publicó la versión española.

83 Leopold-Anton KAUFHOLD, Spanien wie es gegenwärtig ist in physischer, moralischer, politischer, religiöser, statistischer und literarischer Hinsicht aus den Bemerkungen eines Deutschen, während seines Aufenthaltes in Madrid in den Jahren 1790, 1791 und 1792, Gotha: Carl Wilhelm Ettinger, 1797. Christian-August FISCHER, Reise von Amsterdam über Madrid und Cadiz nach Genua in den Jahren 1797 und 1798, Berlin: J. Funger, 1799, con traducciones en francés y en inglés; es también autor de unas Beyträge zur genauern Kenntniss der spanische Besitzungen in Amerika aus den Spanischen übersetzt und mit einigen Anmerkungen von Ch-A. Fischer, Dresden: G. Herlach, 1802. Wilhelm von HUMBOLDT, Diario de viaje a España, 1799-1800. Edición de Miguel Ángel Vega, Madrid: Cátedra, 1998; sobre este viaje del impulsor de la Universidad de Berlín ver Justo GÁRATE, El viaje español de Guillermo de Humboldt (1799-1800), Buenos Aires: Imprenta Ferrari Hermanos, 1946. Heinrich Friedrich LINK, Bemerkungen auf einer Reise durch Frankreich, Spanien und vorzüglich Portugal, Helmstädt und Braunschweig: C.G. Fleckeisen, 1801-1804, con traducciones al

Mundo moderno

Hispania Sacra 55 (2003) 
A. von Humboldt, para la península, Canarias y las posesiones americanas ${ }^{84}$; sin olvidar la del español C. Beramendi ${ }^{85}$.

Todo este material informativo, de procedencia muy variada, con enfoques y perspectivas muy distintos, permite un análisis más contrastado sobre múltiples aspectos de la monarquía hispana, tanto en la metrópoli como en sus posesiones de ultramar, en vísperas de producirse su desmoronamiento. Buena parte de este material ha servido de base documental a los estudiosos que se han ocupado, con fortuna desigual, del reinado de Carlos IV, sea desde un punto de vista general, como sobre cuestiones parciales del mismo. Sobre todo, es de esperar que la publicación, que hoy nos ocupa, sirva para impulsar el estudio de las relacio-

inglés y al francés. Un estudio sobre los viajeros alemanes a España en esta época puede verse en: Werner BRUGGEMANN, «Die Spanienberichte des 18. und 19. Jahrhunderts und ihre Bedeutung für die Formung und Wandlung des deutschen Spaniensbildes», en Gesammelte Aufsätze zur Kulturgeschichte Spaniens, Münster: Aschendorfsche Verlagsbuchhandlung, 12 (1956) 1-146; al que puede añadirse el más reciente de Hans JURETSCHKE (editor), La imagen de España en la Ilustración alemana, Madrid: Görres-Gesellschaft, 1991; y, para Italia, la de $\mathrm{M}^{\mathrm{a}}$. Enriqueta SORIANO PÉREZ-VILlAMIL, España vista por historiógrafos y viajeros italianos (1750-1799), Madrid: Narcea, 1980.

84 Son numerosas las ediciones en alemán, español, francés e inglés, que se han hecho de sus viajes por tierras americanas, de sus ensayos, cartas y otros escritos sobre aquellos países. Entre las más recientes ediciones hechas en español pueden mencionarse: F.H. Alexander von HUMBOLDT, Viaje a las regiones equinociales del nuevo continente, traducción de Lisandro Alvarado, Caracas: Monte Ávila Editores, 1991; Tablas geográfico-politicas del Reino de Nueva España, introducción, trascripción y notas de José G. Moreno, México: UNAM, 1993; el Viaje a las islas Canarias, edición, estudio crítico y notas de Manuel Hernández González, traducción de Lisandro Alvarado, La Laguna: Francisco Lemus, 1995; cabría añadir la edición en microfichas por Jobrand Microfilms Systems, Madrid, 1989, de las obras completas de A. von Humboldt, Gesammelte Werke, Sttugart: Verlag der J.G. Gotta'schen Buchhandlung, 1889, en 12 vols. Sobre este personaje y sus andanzas por la América hispana, la bibliografia disponible es inabarcable; aquí me limito a tres referencias, donde el lector encontrará una escogida selección bibliográfica: Charles MINGUET, Alejandro de Humboldt, historiador y geógrafo de la América española (1799-1804), traducido del francés por Jorge Padín Videla, México: UNAM, 1985; Miguel Ángel PUIG-SAMPER, Consuelo NARANJO OROVIO y Armando GARCÍA GONZÁLEZ (editores), Ensayo político sobre la isla de Cuba. Alejandro de Humboldt, Aranjuez: Doce Calles/Junta de Castilla y León, 1998; y Miguel Ángel PUIG-SAMPER (coord..), Alejandro de Humboldt y el mundo hispánico. La modernidad y la Independencia americana, número monográfico de la revista Debate y Perspectivas. Cuadernos de Historia y Ciencias Sociales, Madrid: Fundación Histórica Tavera, 2000. Muy recientemente se ha despertado el interés por la estancia de este personaje en España: Miguel Ángel PUIG-SAMPER, «Humboldt, un prusiano en la Corte del Rey Carlos IV», en Revista de Indias, Madrid: CSIC, 59 (1999) 329-355; del mismo autor y Sandra REBOK, «Un sabio en la meseta: el viaje de Alejandro de Humboldt a España en 1799», en Revista de Occidente, Madrid: Fundación José Ortega y Gasset, № 254-255 (2002) 95-125. Esta misma revista dedica en su último número, el 260 (Enero de 2003), un monográfico a la literatura de viajes; lo coordinan el mencionado Puig-Samper y Manuel Lucena, en el que colaboran, además, José Luis Peset, Salvador Bernabéu, Juan Pimentel, Oliver Lubrich y Ottmar Ette.

85 Carlos BERAMENDI FREYRE, El pais Valenciano a fines del siglo XVIII, edición, introducción y notas por Emilio Soler Pascual, Alicante: Instituto de Cultura «Juan Gil-Albert», 1994; ha servido a E. Soler para publicar un estudio titulado, El viaje de Beramendi por el País Valenciano (1793-1794), Barcelona: Ediciones del Serbal, 1994. 
nes hispano-austríacas en aquel período de la historia española. Ofrecen éstas un amplio campo a la investigación, escasamente explorado aún, fuera de los meritorios trabajos de $\mathrm{M}^{\mathrm{a}}$. L. Robledo y de H.-O- Kleinmann ${ }^{86}$.

Señalar, por último, que esta colección documental, igual que la dedicada al reinado de Carlos III, forma parte de un proyecto, impulsado por el Instituto Germano-Español de la Sociedad Görres en Madrid, y patrocinado por el Consejo Superior de Investigaciones Científicas. Estaba destinado a promover los estudios sobre España en el período de la Revolución francesa y de la lucha española por su independencia frente a la invasión napoleónica, con especial referencia a la historia de las ideas en relación con la Ilustración y con el desarrollo del constitucionalismo. Ambas instituciones, promotora y patrocinadora, merecen, pues, el pláceme de los investigadores por los logros alcanzados hasta ahora en la realización de tan ambicioso proyecto. Pláceme que debe extenderse a los responsables científicos de tal empeño: el profesor H. Juretschke y su colaborador H.-O. Kleinmann.

Sólo es de lamentar que por causas ajenas a los dos responsables de su elaboración y edición, esta colección se haya detenido en los despachos del año 1795, cuando, en un principio, estaba previsto llegar hasta los últimos años del reinado de Carlos IV. Parece ser que, a raíz de la reunificación alemana, la GörresGesellschaft zur Pflege der Wissenschaft, ante la escasez de recursos económicos para hacer frente a todas sus actividades culturales, decidió volcar su acción hacia los «Länder» de la antigua República Democrática Alemana y hacia los países del Este, en una especie de nuevo Drang nach Osten cultural. En su lugar, la Fundación Biblioteca Alemana Görres de Madrid se ha comprometido únicamente a mantener la Biblioteca creada por el Instituto Germano-Español de Investigación de la Sociedad Görres, sita actualmente en el edificio del Seminario Conciliar de la capital de España. Sus fondos bibliográficos forman una de los mejores bibliotecas, existentes en territorio español, para el estudio de las relaciones históricas y culturales hispano-germanas.

${ }^{86} \mathrm{M}^{\mathrm{a}}$ Luisa, ROBLEDO DEL PRADO, «Relaciones entre España y Austria en el reinado de Carlos IV (1788-1807)», en Hispania, Madrid: CSIC, 46 (1986) 327-351; una buena guía para explorar los fondos archivísticos austríacos es la obra de Pedro VOLTES BOU, Documentos de tema español existentes en el Archivo de Estado de Viena, Barcelona: Instituto Municipal de Historia, 1964-1965, 2 vols. Hans-Otto KLEINMANN, «Las relaciones hispano-austríacas durante el período revolucionario», en la colección documental objeto del presente análisis, I, pp. XXXVII-XLVI, y la versión alemana en pp. XXVII-XXXVI; «España y Austria en la transición del siglo XVIII al XIX», en ibidem, VI, pp. XXVIII-XL, y su versión alemana en pp. XV-XXVII; «Das spanische Kolonialreich in der Politik des Fürsten Kaunitz», en Jahrbuch für Geschichte von Staat, Wirtschaft und Gesellschaft Lateinamerikas, separata, Köln/Graz: Böhlau Verlag, 1968; o su disertación doctoral, Die Politik des Wiener Hofes gegenüber der spanischen Monarchie unter Karl III (1759-1788), Köln, 1967.

Mundo moderno

Hispania Sacra 55 (2003) 